Check for updates

Cite this: Chem. Soc. Rev., 2021, 50,3720

Received 5th September 2020

DOI: $10.1039 / \mathrm{d} 0 \operatorname{cs} 00531 \mathrm{~b}$

rsc.li/chem-soc-rev

\section{Electron deficient borane-mediated hydride abstraction in amines: stoichiometric and catalytic processes}

\author{
Shyam Basak, ${ }^{a}$ Laura Winfrey, ${ }^{b}$ Betty A. Kustiana, ${ }^{a}$ Rebecca L. Melen, (D) *a \\ Louis C. Morrill (D) *a and Alexander P. Pulis (D)*b
}

\begin{abstract}
The manipulation of amino $\mathrm{C}-\mathrm{H}$ bonds has garnered significant interest from the synthetic community due to its inherently high atom, step and redox economy. This Tutorial Review summarises the ability of boranes to mediate hydride abstraction from $\alpha$-amino and $\gamma$-amino conjugated $\mathrm{C}-\mathrm{H}$ bonds. Boranemediated hydride abstraction results in the generation of reactive iminium hydridoborate salts that participate in a variety of stoichiometric and catalytic processes. The reactions that have utilised this unusual reactivity include those that manipulate amino scaffolds (including dehydrogenation, racemisation, isomerisation, $\alpha$ - and $\beta$-functionalisation, and $\mathrm{C}-\mathrm{N}$ bond cleavage) and those that use amine-based reagents (transfer hydrogenation, and alkylation).
\end{abstract}

\section{Introduction}

Hydride transfer is a fundamental reactivity principle that has found numerous applications in synthesis. ${ }^{1,2}$ One of the archetypal examples of which is during the reduction of functional groups via hydride donation from a hydridoborate (a.k.a. borohydride) anion, such as in the conversion of carbonyls to alcohols or imines to amines. $^{2}$ The reverse process (hydride abstraction from a $\mathrm{C}-\mathrm{H}$ bond by a borane, resulting in oxidation of the carbon atom) is far less studied and has found little utility in synthesis (Scheme 1a). However, given the great interest in $\mathrm{C}-\mathrm{H}$ functionalisation strategies in synthesis due to high atom, step and redox economy, the use of borane-mediated hydride abstraction from an organic molecule is being recognised as an efficient route to generate reactive intermediates for downstream chemical processes.

\footnotetext{
${ }^{a}$ Cardiff Catalysis Institute, School of Chemistry, Cardiff University, Main Building, Park Place, Cardiff, CF10 3AT, UK. E-mail: MelenR@cardiff.ac.uk, MorrillLC@cardiff.ac.uk

${ }^{b}$ School of Chemistry, University of Leicester, Leicester, LE1 7RH, UK.

E-mail:a.pulis@leicester.ac.uk
}

There are two general classes of organic substrates that undergo hydride abstraction with an electron deficient borane (1): cyclohexa-1,4-dienes (2) and amines (4 and 6) (Scheme 1b and c). Hydride abstraction involving cyclohexa-1,4-dienes generates Wheland-type intermediates 3 and has been successfully utilised in various hydroelementation processes. This area, pioneered by Oestreich and co-workers, has been recently reviewed. ${ }^{3-5}$

Iminium ions are valuable molecules that are widely applied in synthetic applications, for example in the Mannich reaction, ${ }^{6}$ and are usually formed via the condensation of an amine and a carbonyl derivative. Amines (e.g. 4 and 6) that bear $\alpha$-amino and $\gamma$-amino conjugated $\mathrm{C}-\mathrm{H}$ bonds respectively, undergo boranemediated hydride abstraction to form iminium hydridoborate salts (5 and 7). This strategy is complementary to traditional approaches as the reactive iminium is formed directly from the parent amine in situ. In addition, there is great interest from the synthetic community, especially from the pharmaceutical industry, ${ }^{7}$ in efficient synthetic methods involving the $\mathrm{C}-\mathrm{H}$ functionalisation of amines. Borane-mediated hydride abstraction in amines has provided an unusual but powerful method to mediate amine $\mathrm{C}-\mathrm{H}$ 
functionalisation reactions and to activate amine-based reagents. This is reflected in the recent flurry of reports that utilise this reactivity.

This Tutorial Review will summarise processes involving borane-mediated hydride abstraction of amino $\mathrm{C}-\mathrm{H}$ bonds. In both cases of $\alpha$ - and $\gamma$-amino conjugated hydride abstraction, the use of stoichiometric borane and then borane-catalysed processes are described. The use of tris(pentafluorophenyl)borane, $\mathrm{B}\left(\mathrm{C}_{6} \mathrm{~F}_{5}\right)_{3}$, will be most frequently encountered in this context, but other boranes have also been explored more recently. We will also describe the proposed mechanistic steps and catalytic cycles that underpin these processes, focussing on the fate of both the iminium moiety and the hydridoborate counterion.

\section{Borane-mediated $\alpha$-amino hydride abstraction}

\subsection{Stoichiometric studies}

This section will introduce the array of amines that undergo borane-mediated $\alpha$-amino hydride abstraction with a stoichiometric

quantity of borane, including zirconium and zinc coordinated $\mathrm{N}$-compounds, $\mathrm{N}$-aryl amines, aliphatic tertiary amines, as well as intramolecular hydride transfer. The following sections are organised based on the fate of the resultant iminium hydridoborate salt (observation only, proton transfers, nucleophilic addition to the iminium moiety, and further hydride transfer), although there will be some overlap between these topics.

2.1.1 Observation of iminium hydridoborates. In 1995, Erker and co-workers reported a borane-mediated $\alpha$-amino hydride abstraction during the reaction of alkyl(amido)zirconocene complexes 8 with $\mathrm{B}\left(\mathrm{C}_{6} \mathrm{~F}_{5}\right)_{3}$ (Scheme 2). ${ }^{8}$ Initially, the $\mathrm{B}\left(\mathrm{C}_{6} \mathrm{~F}_{5}\right)_{3}$-mediated methyl abstraction from amidomethylzirconocene 8 formed amidozirconocene cation $\mathbf{9}$. The ion pair $\mathbf{9}$ was found to be thermally labile and eliminated methane to form hydridoborate based ion pair 11, which was proposed to be formed as a result of borane-mediated $\alpha$-amino hydride abstraction from intermediate $\mathbf{1 0 .}$

The first example of borane-mediated $\alpha$-amino hydride abstraction from simple amines was reported by Santini and co-workers in 2002 during NMR analysis of mixtures of dialkyl

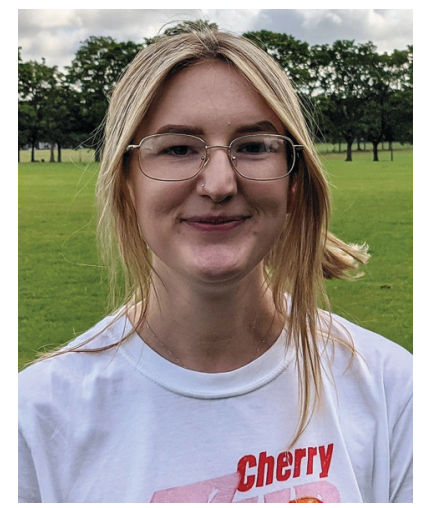

Laura Winfrey

Laura Winfrey completed her Dr Shyam Basak obtained his PhD from Indian Institute of Technology Kharagpur under the supervision of Prof. Dipakranjan Mal in 2017. Then he joined the group of Prof. Amit Basak as a research associate in the same institute for one year. In 2018, he moved to UK to pursue postdoctoral research at Cardiff University in the lab of Dr Louis Morrill to work in the field of FLP chemistry in collaboration with Dr Rebecca Melen. Currently, he Shyam Basak is continuing as a postdoctoral researcher in the Morrill group to work on synthetic organic electrochemistry.

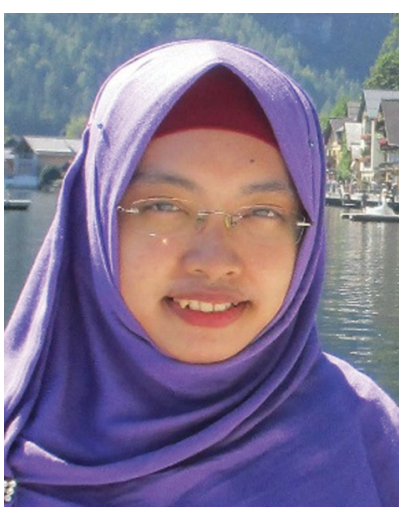

Betty A. Kustiana
Betty A. Kustiana received a Master in Chemistry at University of Copenhagen and is currently pursuing her PhD at Cardiff University focused on the main group catalysis.
MChem degree with a year abroad in 2019 at the University of Leicester (UK) and Kent State University (USA). Laura is currently studying for her PhD at the University of Leicester with $\mathrm{Dr}$ Alex Pulis where she is discovering new catalytic methods for the sustainable synthesis of amines.

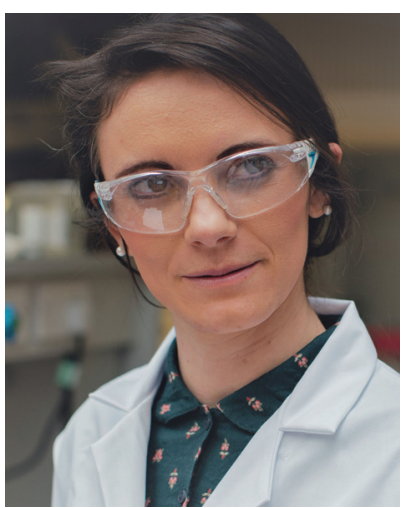

Rebecca L. Melen
Dr Rebecca Melen studied for her $\mathrm{PhD}$ degree at the University of Cambridge (UK). Following Postdoctoral studies in Toronto (Canada) and Heidelberg (Germany), she took up a position at Cardiff University (UK) in 2014 where she is now a Reader in Inorganic Chemistry. In 2018, she was awarded an EPSRC early career fellowship and she was the 2019 recipient of the RSC Harrison Meldola Memorial Prize. Her research interests include diverse aspects of main group reactivity and catalysis, including the applications of main group chemistry in organic synthesis. 
a) Borane-mediated hydride abstraction from $\mathrm{C}-\mathrm{H}$ bonds

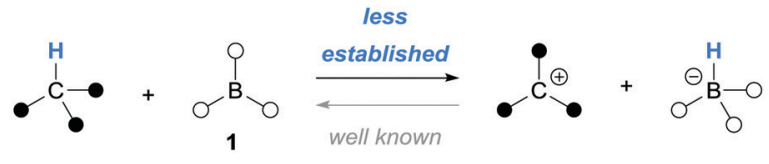

b) Cyclohexa-1,4-dienes - previously reviewed

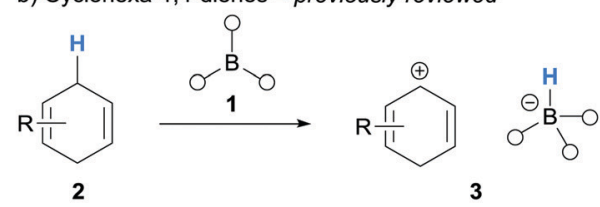

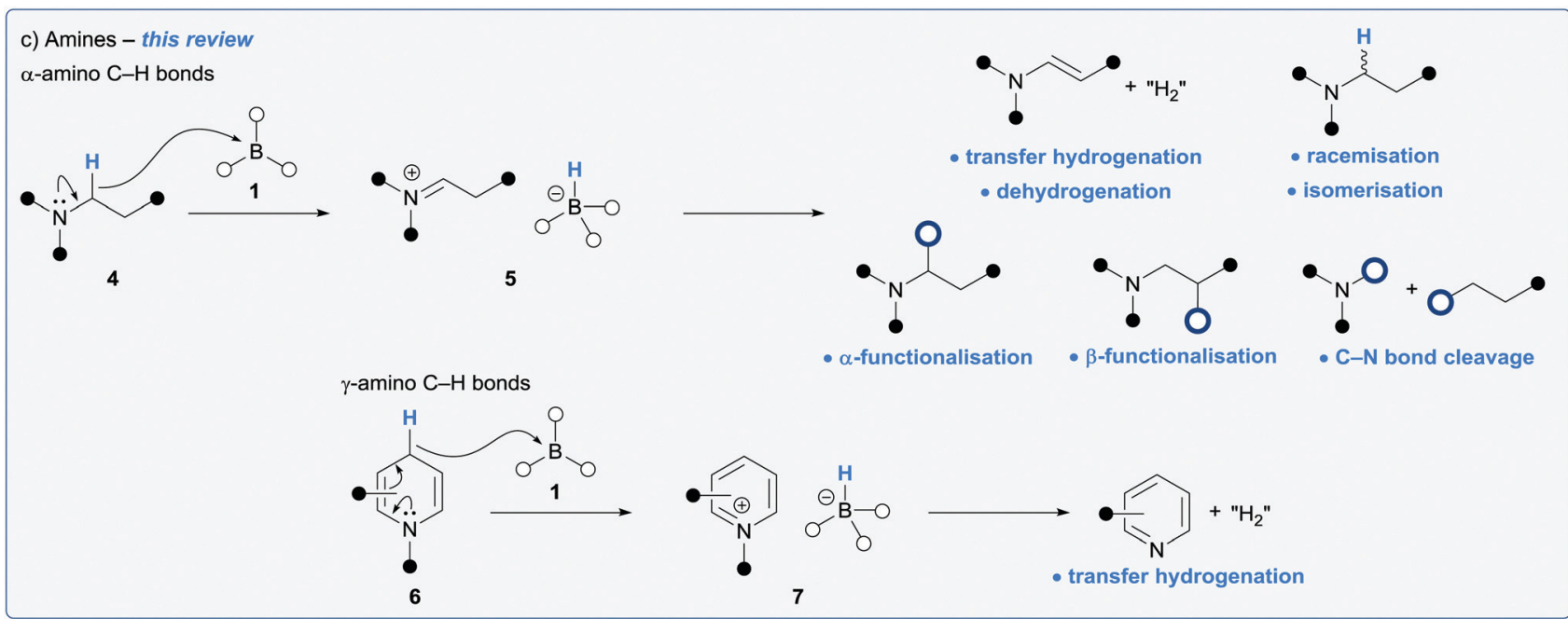

Scheme 1 Electron deficient borane-mediated hydride abstraction from $\mathrm{C}-\mathrm{H}$ bonds.

anilines and $\mathrm{B}\left(\mathrm{C}_{6} \mathrm{~F}_{5}\right)_{3}$ (Scheme 3). ${ }^{9}$ In the case of dimethylaniline (12a), Lewis acid-base pairs 13a were observed along with iminium hydridoborate ion pair 14a, where the latter presumably forms as a result of borane-mediated hydride abstraction. On the other hand, diethyl aniline (12b) formed ammonium hydridoborate ion pair 15 and a mixture of $E$ - and $Z$-iminium-borate zwitterions 17. Zwitterions $\mathbf{1 7}$ are formed as a result of proton transfer from iminium $14 \mathrm{~b}$ to diethyl aniline (12b) and subsequent addition of enamine 16 to $B\left(\mathrm{C}_{6} \mathrm{~F}_{5}\right)_{3}$. Further examples of the formation of iminium hydridoborates and subsequent proton transfers are given in Section 2.1.2.

In 2006, Chen and co-workers reported that binuclear zinc enolate complexes 18 in combination with $B\left(C_{6} F_{5}\right)_{3}$, form cationic zinc enolates $\mathbf{1 9}$, which were found to be highly active catalysts for acrylate polymerisation (Scheme 4). ${ }^{10}$

In 2012, as part of a study of amine/B( $\left.\mathrm{C}_{6} \mathrm{~F}_{5}\right)_{3}$ frustrated Lewis pairs, Erker, Stephan and co-workers further expanded the range of amines that undergo borane-mediated hydride abstraction. ${ }^{11}$ It was found that $N, N$-dimethylaniline (12a), used as supplied, reacted with $\mathrm{B}\left(\mathrm{C}_{6} \mathrm{~F}_{5}\right)_{3}$ to produce the iminium-borohydride ion pair 14a, as in the study by Santini and co-workers. ${ }^{9}$ In contrast, hydride abstraction was not observed when $\mathrm{N}, \mathrm{N}$-dimethylaniline (12a) was carefully purified and the reaction was performed under rigorously dry conditions. The reaction of $\mathrm{N}$-isopropyl aniline (20) with $\mathrm{B}\left(\mathrm{C}_{6} \mathrm{~F}_{5}\right)_{3}$ resulted in hydride abstraction, where iminiumhydridoborate $\mathbf{2 1}$ was a minor component of an equilibrium

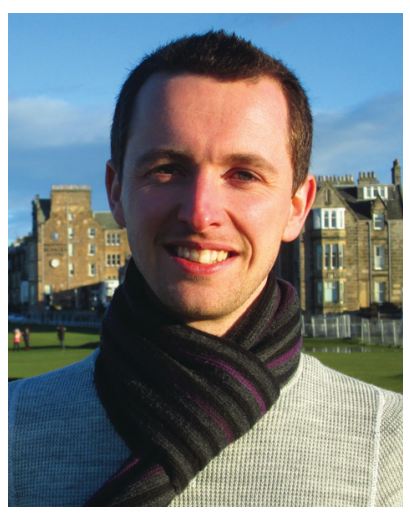

Louis C. Morrill
Dr Louis Morrill received his $P h D$ from the University of St Andrews in 2014 under the direction of Prof. Andrew Smith and undertook postdoctoral research at UC Berkeley with Prof. Richmond Sarpong. In June 2015, he initiated his independent research career at Cardiff University. Research in the group is focused on inventing new reactions in organic chemistry and developing sustainable catalytic methodologies for synthesis.

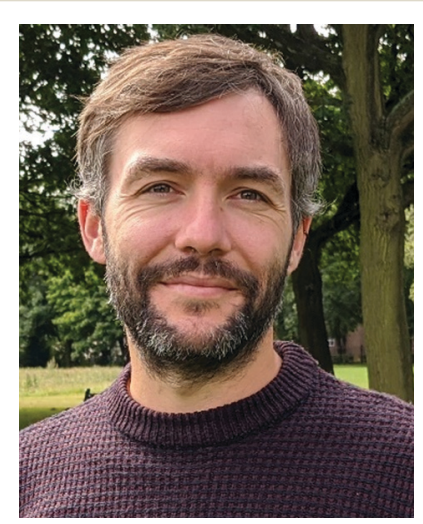

Alexander P. Pulis
Dr Alex Pulis obtained his PhD from the University of Bristol (UK) under the guidance of Prof. Varinder K. Aggarwal. In 2014, he joined Prof. Douglas Stephan at the University of Toronto (Canada) for postdoctoral studies. He then moved to the University of Manchester (UK) as a fixed term Lecturer within the group of Prof. David J. Procter. Alex began his independent career at the University of Leicester (UK) in 2018 where he explores the reactivity of main group elements and applies these finding to challenges in chemical synthesis. 
<smiles>[R]CN(C[R])[14C]([R])(C)[Na]</smiles>

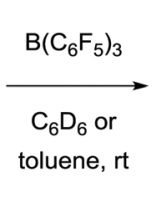

$\mathrm{R}=\mathrm{Me}$ or $\mathrm{R}-\mathrm{R}=-\left(\mathrm{CH}_{2}\right)_{3}-$<smiles></smiles>

10

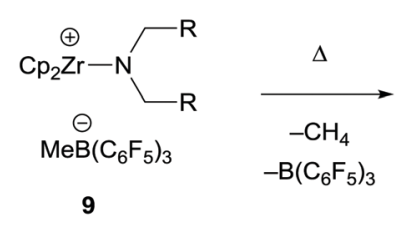

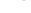

$$
\begin{gathered}
\mathrm{R}=\mathrm{Me}, 84 \% \\
\mathrm{R}-\mathrm{R}=-\left(\mathrm{CH}_{2}\right)_{3^{-}}, \text {not isolated }
\end{gathered}
$$

Scheme $2 \mathrm{~B}\left(\mathrm{C}_{6} \mathrm{~F}_{5}\right)_{3}$-mediated $\alpha$-amino hydride abstraction in the formation of $\left(\eta^{2}\right.$-iminoacyl)zirconocene cations. $\mathrm{Cp}=$ cyclopentadienyl.

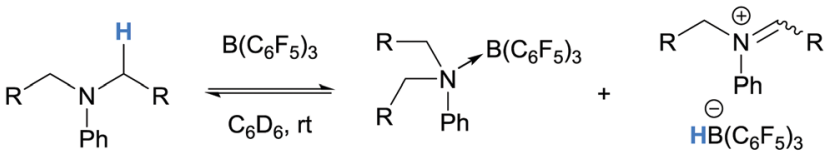

$$
\begin{aligned}
& \text { 12a, } \mathrm{R}=\mathrm{H} \\
& \text { 12b, } R=M e \\
& \text { 13a, } \mathrm{R}=\mathrm{H} \\
& \text { 13b, } \mathrm{R}=\mathrm{Me} \\
& \text { 14a, } \mathrm{R}=\mathrm{H} \\
& \text { 14b, } R=M e \\
& \text { ॥ } \mathrm{R}=\mathrm{Me}
\end{aligned}
$$
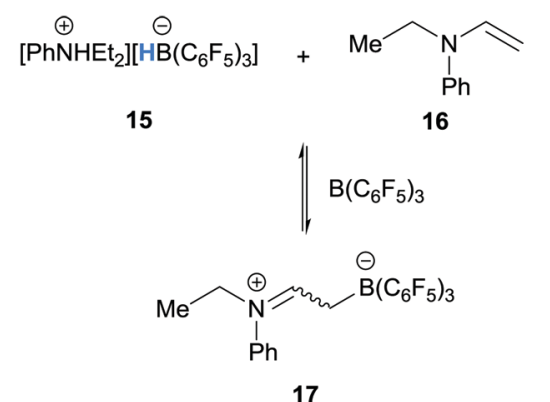

Scheme $3 B\left(C_{6} F_{5}\right)_{3}$-mediated $\alpha$-amino hydride abstraction from $N, N$ dialkylanilines.

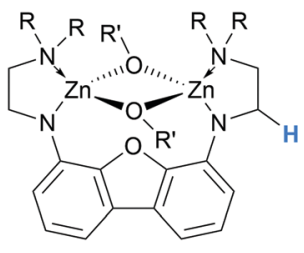

18

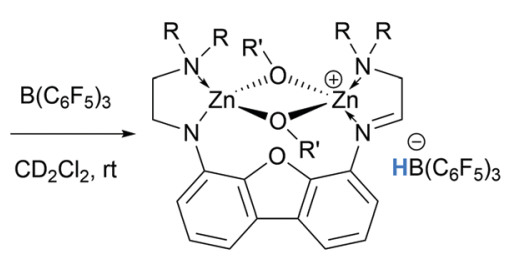

19a, $R=M e, i-P r$, quantitative

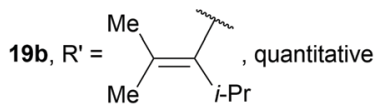

Scheme $4 \quad B\left(C_{6} F_{5}\right)_{3}$-mediated $\alpha$-amino hydride abstraction in from cationic zinc enolates.

with adduct 22 (Scheme $5 \mathrm{a}$ ). On treatment of $\mathrm{B}\left(\mathrm{C}_{6} \mathrm{~F}_{5}\right)_{3}$ with 1,4$\mathrm{C}_{6} \mathrm{H}_{4}\left(\mathrm{CH}_{2} \mathrm{NH} t-\mathrm{Bu}\right)_{2}(23)$, hydride abstraction was also observed in addition to mono- and bis-amine-borane adducts 25 and 26 a)

20

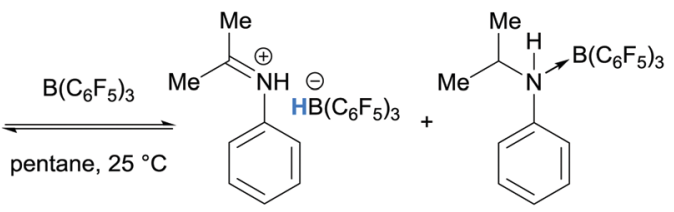

$21,10 \%$

(w.r.t. 22)

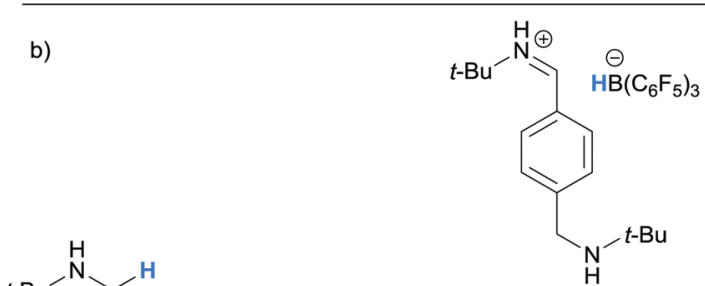

24, 33\%

(w.r.t. 25 and 26)

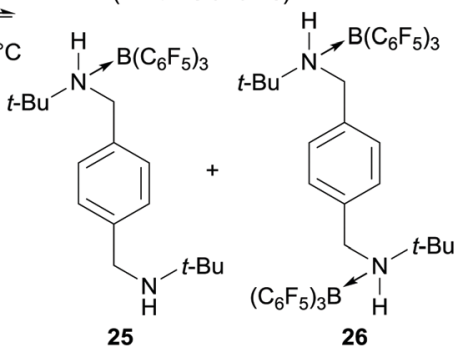

Scheme $5 \quad B\left(C_{6} F_{5}\right)_{3}$-mediated $\alpha$-amino hydride abstraction from secondary amines.

(Scheme 5b). On the other hand, hydride abstraction was not observed in the reaction of benzyldimethyl amine and $\mathrm{B}\left(\mathrm{C}_{6} \mathrm{~F}_{5}\right)_{3}$.

2.1.2 Formation of iminium hydridoborates and subsequent proton transfer. As demonstrated by Santini and co-workers (Scheme 3), ${ }^{9}$ when the iminium hydridoborate salts generated after hydride abstraction contain $\beta$-hydrogens, proton transfer is possible. Reports from Mercandelli, D'Alfonso, Resconi and co-workers, ${ }^{12}$ Rieger, Repo and co-workers, ${ }^{13}$ and Berke and co-workers ${ }^{14}$ have shown that a variety of secondary and tertiary aliphatic amines 27 undergo borane-mediated hydride abstraction with $\mathrm{B}\left(\mathrm{C}_{6} \mathrm{~F}_{5}\right)_{3}$ to form the corresponding iminium hydridoborate salts 28 (Scheme 6). The salts 28 are deprotonated in situ by another equivalent of amine 27 to form enamines $\mathbf{3 0}$ and ammonium-hydridoborates 29 . The nucleophilic enamines $\mathbf{3 0}$ subsequently trap $\mathrm{B}\left(\mathrm{C}_{6} \mathrm{~F}_{5}\right)_{3}$ to form zwitterions 31 .

In a related process, Focante and co-workers, and Resconi and co-workers showed that the reaction of $N$-methylindoline (32) and $\mathrm{B}\left(\mathrm{C}_{6} \mathrm{~F}_{5}\right)_{3}$ forms ammonium-hydridoborate 35 and zwitterion 36 (Scheme 7). ${ }^{15,16}$ In this case, $\mathrm{B}\left(\mathrm{C}_{6} \mathrm{~F}_{5}\right)_{3}$-mediated hydride abstraction of indoline 32 and subsequent deprotonation of the iminium hydridoborate salt $\mathbf{3 3}$ forms a mixture of ammoniumhydridoborate 35 and indole $\mathbf{3 4}$. The reaction of indole $\mathbf{3 4}$ and $\mathrm{B}\left(\mathrm{C}_{6} \mathrm{~F}_{5}\right)_{3}$ is known to form zwitterion $36 .{ }^{17}$

2.1.3 Formation of iminium hydridoborates and subsequent intramolecular nucleophilic addition to the iminium ion. In addition to deprotonation events, the iminium hydridoborate salts can undergo addition processes with pendant nucleophiles. 

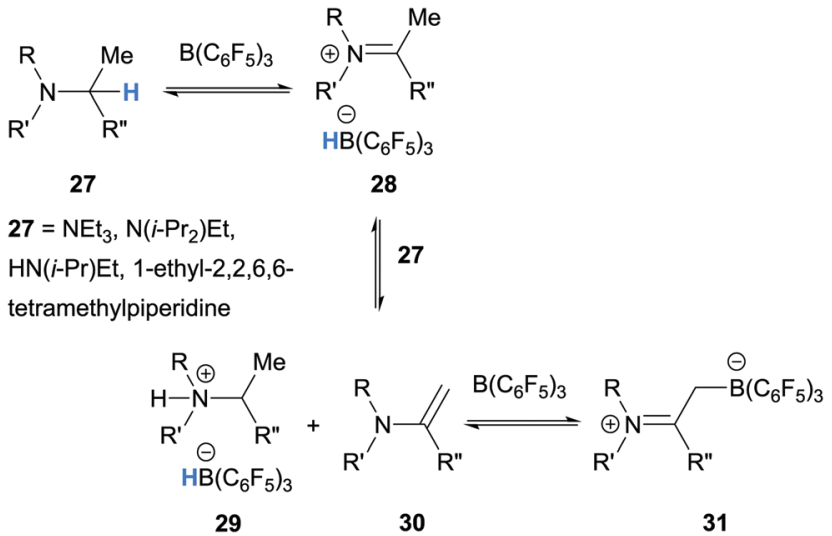

Scheme $6 \mathrm{~B}\left(\mathrm{C}_{6} \mathrm{~F}_{5}\right)_{3}$-mediated $\alpha$-amino hydride abstraction from aliphatic tertiary amines.

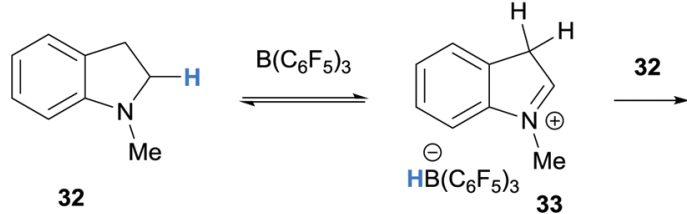

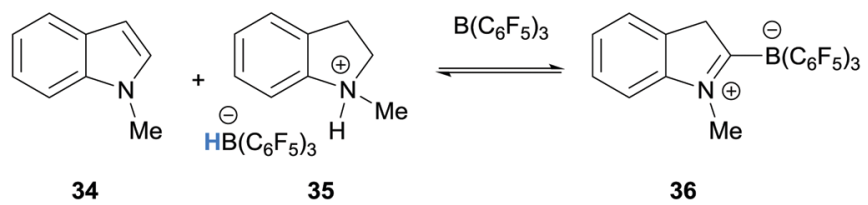

Scheme $7 \quad B\left(C_{6} F_{5}\right)_{3}$-mediated $\alpha$-amino hydride abstraction from $N$-methylindoline.

Grimme, Erker and co-workers performed a combined theoretical and experimental study on the generation and stability of $\alpha$-ferrocenyl carbenium ions. Hydride abstraction was observed in the reaction of ( \pm -dimethylamino-[3]ferrocenophanes $( \pm)$-37a and $( \pm)-37 \mathbf{b}$ with $\mathrm{B}\left(\mathrm{C}_{6} \mathrm{~F}_{5}\right)_{3}$ and the ferrocene stabilised iminium hydridoborate salts $( \pm)-38 \mathbf{a}$ and $( \pm)$-38b were formed (Scheme 8). ${ }^{18-20}$ The iminium moiety in 38a was also hydrolysed to form $( \pm)$-ferrocenophane ketone $( \pm)-39 .^{19}$

Analogous ferrocenophanes $( \pm)-37 \mathrm{c}$ and $( \pm)$-37d also underwent hydride abstraction with $\mathrm{B}\left(\mathrm{C}_{6} \mathrm{~F}_{5}\right)_{3}$. In both cases, $( \pm)-37 \mathrm{c}$ and $( \pm)-37 \mathbf{d}$ appeared to undergo hydride abstraction at the $\mathrm{N}-\mathrm{CH}_{3}$ substituent (rather than the C-secondary amino $\mathrm{C}-\mathrm{H}$ bond as in $( \pm)-\mathbf{3 7 a}$ and $( \pm)-\mathbf{3 7 b})$ resulting in formation of $( \pm)-40 \mathbf{c}$ and $( \pm)-41 .^{21}$

In iminium hydridoborate $( \pm)-38 c$, the pendant phosphine moiety traps the electrophilic iminium carbon to form phosphonium salt $( \pm)$-40c. Similarly, $( \pm)-38 d$, that bears a pendant imine, forms $( \pm)$-41 via intermediate $( \pm)$-40d (Scheme 8 ).

In a related process, Mercandelli, D'Alfonso, Resconi and coworkers reported the intramolecular trapping of iminium hydridoborate 43 , generated via $\mathrm{B}\left(\mathrm{C}_{6} \mathrm{~F}_{5}\right)_{3}$-mediated hydride abstraction in 1,8-bis(dimethylamino)naphthalene (42), with a pendant amino group (Scheme 9). ${ }^{22}$

2.1.4 Formation of iminium hydridoborates and subsequent hydride transfer to electron deficient $\pi$-bonds. The hydridoborate

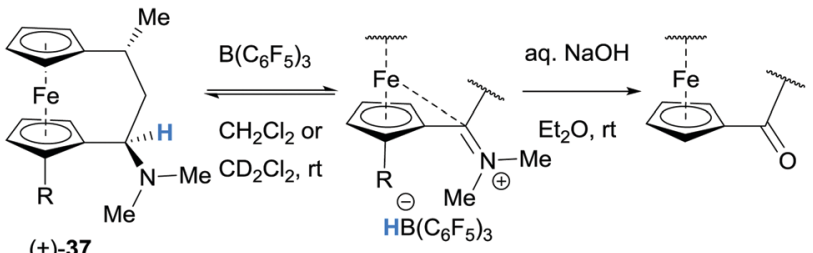

$( \pm)-37$

\begin{tabular}{|ll}
$B\left(C_{6} F_{5}\right)_{3}$ & $( \pm)-38 a, R=H, 74 \%$ \\
rt & $( \pm)-38 b, R=$ vinyl, not isolated
\end{tabular}$\quad( \pm)-39, R=H, 84 \%$
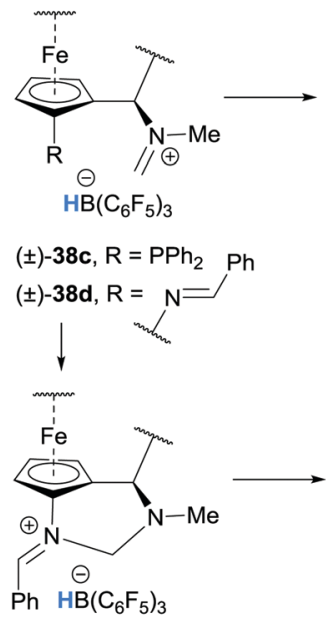

$( \pm)-40 \mathrm{~d}$

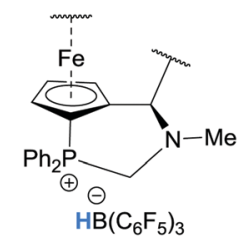

$( \pm)-40 c, 75 \%$

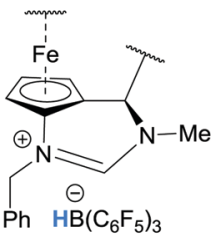

$( \pm)-41,86 \%$
Scheme $8 \quad B\left(C_{6} F_{5}\right)_{3}$-mediated $\alpha$-amino hydride abstraction from dimethylamino-[3]ferrocenophanes $( \pm)-37$ and resultant reactivity.<smiles>CN(C)c1cccc2cccc(N(C)C)c12</smiles>

42

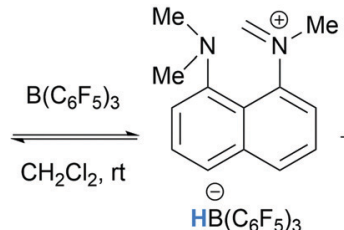

43

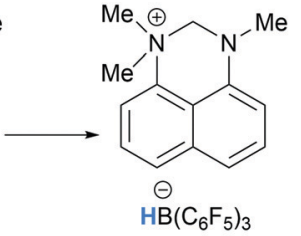

44
Scheme $9 \mathrm{~B}\left(\mathrm{C}_{6} \mathrm{~F}_{5}\right)_{3}$-mediated $\alpha$-amino hydride abstraction from 1,8-bis(dimethylamino)naphthalene $\mathbf{4 2}$ and resultant intramolecular nucleophilic addition.

counterion, formed after borane-mediated hydride transfer, can also participate in downstream reactivity, such as hydride transfer to electron deficient alkenes. This process often triggers further reactivity, such as transfer hydrogenation and $\mathrm{C}-\mathrm{C}$ bond forming reactions.

In 2015, Chen and co-workers studied the application of a $\mathrm{Et}_{3} \mathrm{~N} / \mathrm{B}\left(\mathrm{C}_{6} \mathrm{~F}_{5}\right)_{3}$ Lewis pair towards the polymerisation of acrylate monomers. ${ }^{23}$ Instead of polymerisation taking place, a mixture of $\mathrm{Et}_{3} \mathrm{~N} / \mathrm{B}\left(\mathrm{C}_{6} \mathrm{~F}_{5}\right)_{3} /$ methyl methacrylate (45) (1:2:1) afforded methyl isobutyrate 46 in quantitative yield (Scheme 10a). NMR experiments revealed that upon mixing $\mathrm{Et}_{3} \mathrm{~N}, \mathrm{~B}\left(\mathrm{C}_{6} \mathrm{~F}_{5}\right)_{3}$ and methyl methacrylate in a $1: 1: 1$ ratio, a mixture of zwitterion 47 and ammonium-hydridoborate salt 48 was formed. This observation was in line with previous reports of borane-mediated $\alpha$-amino hydride abstraction followed by deprotonation of the 
a)<smiles>C=C(C)C(=O)OC</smiles>

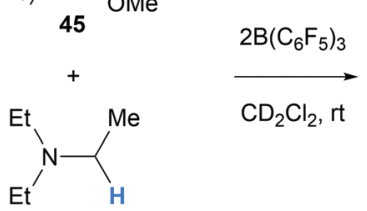

b)
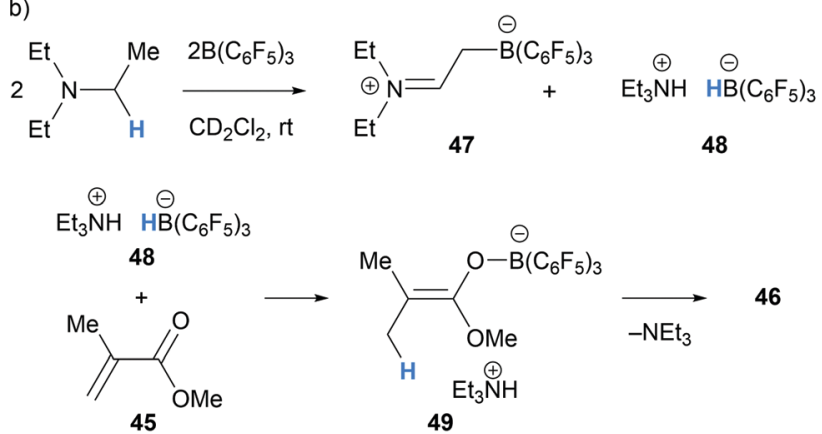

Scheme $\left.10 \quad \mathrm{~B}_{(} \mathrm{C}_{6} \mathrm{~F}_{5}\right)_{3}$-mediated $\alpha$-amino hydride abstraction utilised in transfer hydrogenation of methyl methacrylate.

iminium hydridoborate salt as described above in Section 2.1.2. The addition of one further equivalent of $\mathrm{B}_{(}\left(\mathrm{C}_{6} \mathrm{~F}_{5}\right)_{3}$ presumably activates methyl methacrylate (45) for reduction by the hydridoborate counterion in $\mathbf{4 8}$ (Scheme 10b). Subsequent proton transfers in salt 49 results in the formation of the hydrogenated product 46.

In 2017, Erker and co-workers undertook experimental and theoretical studies on the $\mathrm{B}\left(\mathrm{C}_{6} \mathrm{~F}_{5}\right)_{3}$-mediated $\alpha$-amino hydride abstraction from $N$-methyl amines in the presence of electron deficient alkynes and alkenes (Schemes 11 and 12). ${ }^{24}$ In all cases, the generated hydridoborate counterions in the iminium salts $(c f$. 14a-14b) reduced the electron deficient alkyne or alkene to form an enolate $(c f . \mathbf{5 3}, \mathbf{5 9}, \mathbf{6 4})$. The nucleophilic enolates reacted with the iminium electrophile in a Mannichtype process to form new $\mathrm{C}-\mathrm{C}$ bonds. In the case of the reaction of $N, N$-dimethylmesitylamine (50), dimethylacetylenedicarboxylate (51) and $\mathrm{B}\left(\mathrm{C}_{6} \mathrm{~F}_{5}\right)_{3}$, a nucleophilic allenoate $\mathbf{5 3}$ is formed. After $\mathrm{C}-\mathrm{C}$ bond formation, the resulting product $\mathbf{5 4}$ isomerised to zwitterion 55 (Scheme 11a). An analogous process was reported in the reaction of 1,2,2,6,6-pentamethylpiperidine (56) and dimethylacetylenedicarboxylate (51) and $\mathrm{B}\left(\mathrm{C}_{6} \mathrm{~F}_{5}\right)_{3}$ (Scheme 11b).

Similar reactivity was also observed when $\alpha, \beta$-unsaturated carbonyl compounds were used (Scheme 12). In the case of $N$-phenyl-maleimide (58), hydride abstraction and subsequent transfer generated enolate 59, which then added to the iminium carbon in 52 to form succinamide $\mathbf{6 0}$. The reaction of ethyl acrylate (61), amine 50 and $\mathrm{B}\left(\mathrm{C}_{6} \mathrm{~F}_{5}\right)_{3}$ initially followed a similar course and formed Mannich product 65. However, 65 also underwent further $\mathrm{B}_{(}\left(\mathrm{C}_{6} \mathrm{~F}_{5}\right)_{3}$-mediated hydride abstraction to form iminium hydridoborate $\mathbf{6 6}$, which after proton transfer, resulted in the transfer hydrogenation of ethyl acrylate to form ethyl propionate (63).
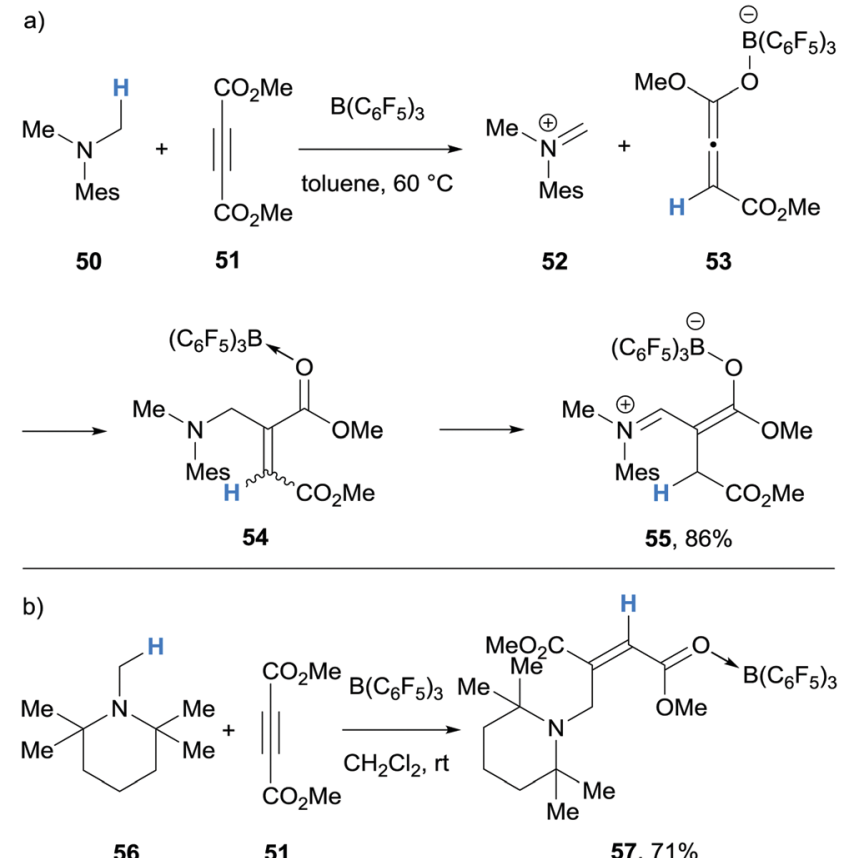

Scheme $11 \mathrm{~B}\left(\mathrm{C}_{6} \mathrm{~F}_{5}\right)_{3}$-mediated $\alpha$-amino hydride abstraction and subsequent hydride transfer to electron deficient alkynes utilised in $\mathrm{C}-\mathrm{C}$ bond forming reactions. Mes = 2,4,6-trimethylphenyl.

2.1.5 Intramolecular $\alpha$-amino hydride abstraction. The majority of borane-mediated $\alpha$-amino hydride abstraction has been reported with $\mathrm{B}\left(\mathrm{C}_{6} \mathrm{~F}_{5}\right)_{3}$. However, $\alpha$-amino hydride abstraction can also be mediated with heteroleptic boranes that have fewer perfluoro aryl rings and are therefore weaker Lewis acids.

In 2011, Repo and co-workers observed racemisation during the synthesis of an ammonium hydridoborate 69 from enantioenriched amine 68 (>99:1 e.r., Scheme 13a). ${ }^{25}$ To explain this observation, it was proposed that the intermediate amino borane 70, underwent reversible intramolecular hydride abstraction from the $\alpha$-amino $\mathrm{C}-\mathrm{H}$ bond to the $\mathrm{B}\left(\mathrm{C}_{6} \mathrm{~F}_{5}\right)_{2}$ moiety giving 71 (Scheme 13b).

During a study of ethylene and hexylene bridged amino borane FLPs, Erker and co-workers reported the synthesis of zwitterions $\mathbf{7 4}$ from amino borane 72 (Scheme 14). ${ }^{26}$ In this case, intramolecular hydride abstraction from the $\alpha$-amino $\mathrm{C}-\mathrm{H}$ bond to the $\mathrm{B}\left(\mathrm{C}_{6} \mathrm{~F}_{5}\right)_{2}$ moiety generated iminium hydridoborate 73 that reduced benzaldehyde or benzophenone yielding $\mathbf{7 4}$.

In 2012, Mitzel and co-workers reported the formation of cyclic iminium borate 80 in the reaction between $\mathrm{HB}\left(\mathrm{C}_{6} \mathrm{~F}_{5}\right)_{2}$ and $N, N$-diisopropylallylamine (75a) (Scheme 15$){ }^{27}$ The formation of 80 was proposed to proceed via hydroboration of $75 \mathrm{a}$ with $\mathrm{HB}\left(\mathrm{C}_{6} \mathrm{~F}_{5}\right)_{2}$ to form amino borane 76a. Intramolecular borane-mediated hydride abstraction in $\mathbf{7 6 a}$ formed iminium hydridoborate zwitterion 77 , which underwent proton transfer generating enaminium hydridoborate 78 . Dehydrogenation of 78 then allowed for intramolecular nucleophilic addition of the enamine moiety to the three-coordinate borane in $\mathbf{7 9}$ to form the cyclic product $\mathbf{8 0}$. In contrast, less hindered allyl amines, such as diethylallylamine (75b), did not form the analogous 

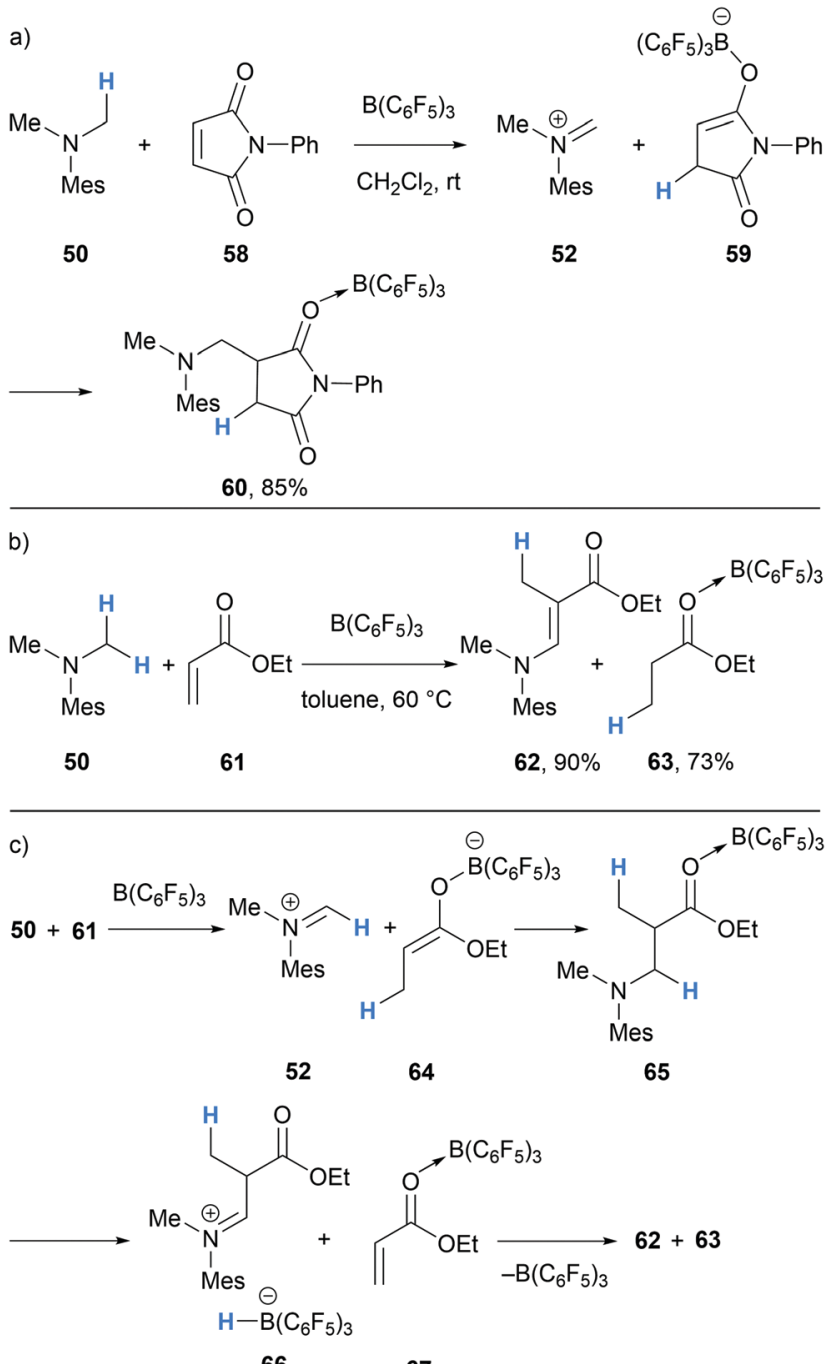

Scheme $12 \mathrm{~B}\left(\mathrm{C}_{6} \mathrm{~F}_{5}\right)_{3}$-mediated $\alpha$-amino hydride abstraction and subsequent hydride transfer to electron deficient alkenes utilised in $\mathrm{C}-\mathrm{C}$ bond forming reactions.

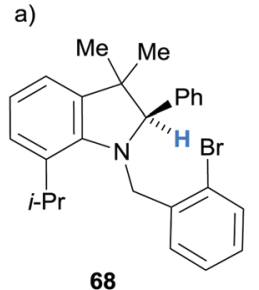

$>99: 1$ e.r.

b)

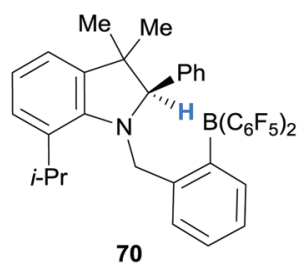

Scheme 13 Borane-mediated intramolecular $\alpha$-amino hydride abstraction and racemisation.

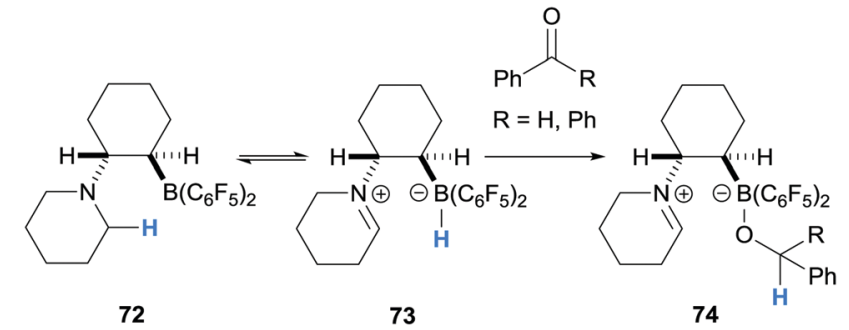

Scheme 14 Borane-mediated intramolecular $\alpha$-amino hydride abstraction and subsequent carbonyl reduction.

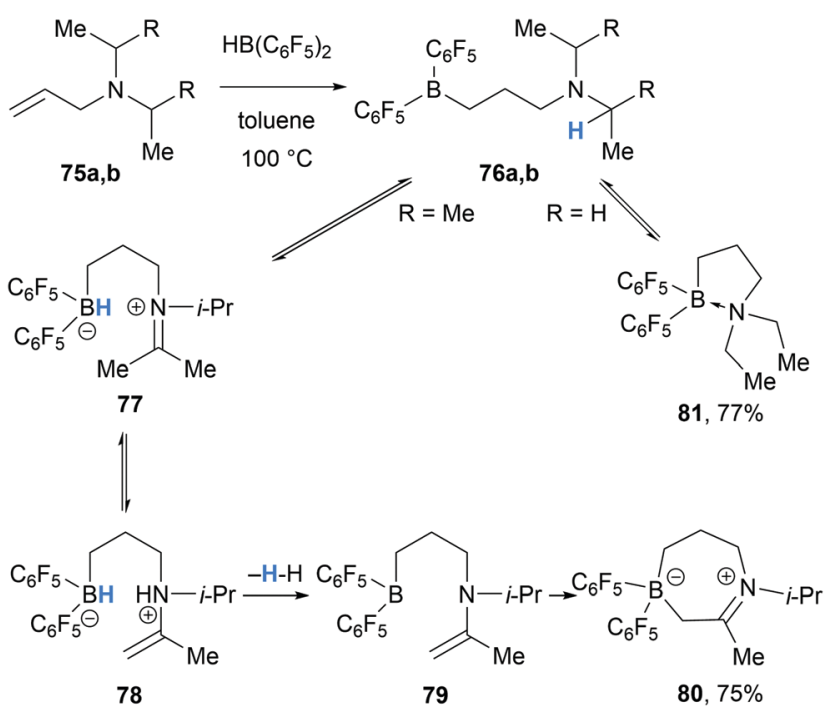

Scheme 15 Borane-mediated intramolecular $\alpha$-amino hydride abstraction and subsequent dehydrogenation and cyclisation.

cyclic product, and instead formed intramolecular Lewis adduct $\mathbf{8 1}$.

In a related reaction, Mitzel and co-workers reported the formation of seven-membered iminium-borate $\mathbf{8 6}$ during the hydroboration of $N, N$-diallyl- $N$-tert-butylamine (82) with $\mathrm{HB}\left(\mathrm{C}_{6} \mathrm{~F}_{5}\right)_{2}$ (Scheme 16). ${ }^{28}$ In line with previous reports, mono-hydroboration of 82 generated the amino borane 83 which undergoes intramolecular $\alpha$-amino hydride abstraction to form $\alpha, \beta$-unsaturated iminium hydridoborate $\mathbf{8 4}$. We propose that iminium-borate $\mathbf{8 4}$

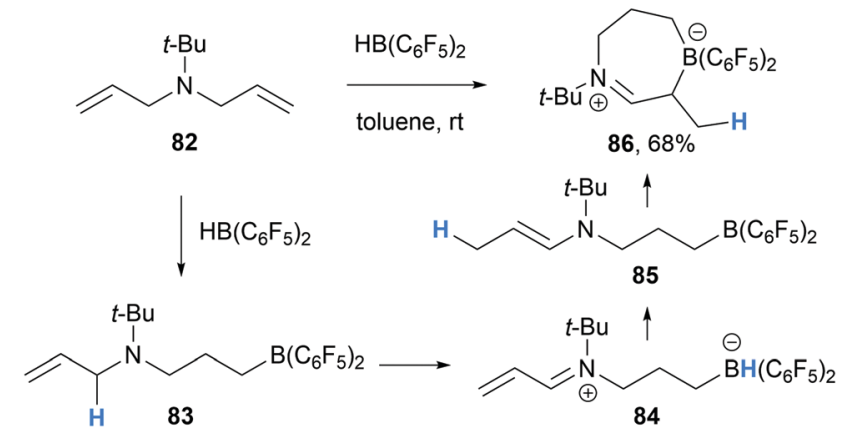

Scheme 16 Borane-mediated intramolecular $\alpha$-amino hydride abstraction and subsequent hydride transfer and cyclisation. 


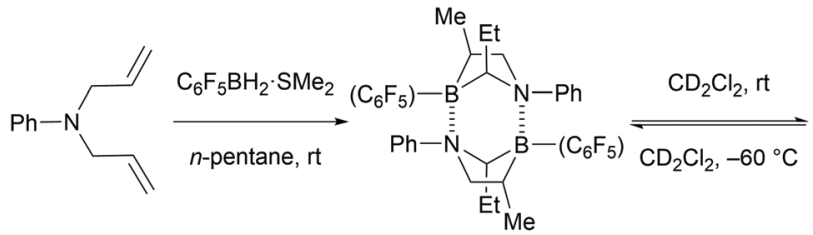

87

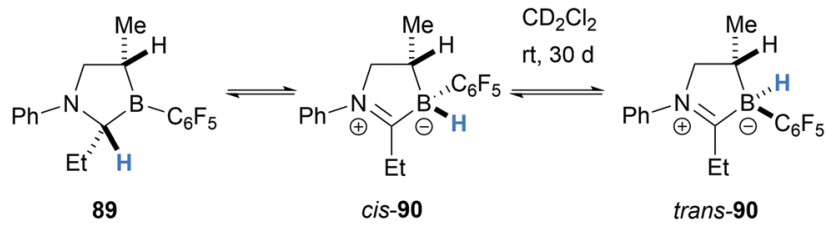

Scheme 17 1,2-Hydride migration from an $\alpha$-amino $\mathrm{C}-\mathrm{H}$ bond to a borane atom.

then undergoes intramolecular conjugate reduction from the hydridoborate moiety to the $\beta$-position of the $\alpha, \beta$-unsaturated iminium 84. The generated enamine 85 intramolecularly traps the electrophilic borane moiety to form the cyclic zwitterion $\mathbf{8 6}$.

In 2016, Erker and co-workers reported an interesting 1,2hydride migration from an $\alpha$-amino $\mathrm{C}-\mathrm{H}$ bond to a borane atom (Scheme 17). ${ }^{29}$ The dimer 88 was formed after double hydroboration of $\mathrm{N}, \mathrm{N}$-diallylaniline (87) with $\mathrm{C}_{6} \mathrm{~F}_{5} \mathrm{BH}_{2}$. Under dilute conditions, dimer $\mathbf{8 8}$ dissociates to form monomer $\mathbf{8 9}$ which can undergo the stereospecific 1,2-hydride migration to form cis-iminium-hydridoborate zwitterion 90. The cis-isomer 90 slowly equilibrates to a 1:1 mixture with the trans-isomer, presumably via intermolecular hydride transfer.

\subsection{Catalytic applications}

Borane-mediated $\alpha$-amino hydride abstraction has been successfully utilised in a variety of catalytic manifolds by virtue of the range of processes by which the hydridoborate counterion can react in downstream processes. In this section we will discuss borane-catalysed transfer hydrogenation, dehydrogenation, racemisation, isomerisation, $\alpha$ - and $\beta$-functionalisation of amines, and processes that involve $\mathrm{C}-\mathrm{N}$ bond cleavage. All of these transformations are made possible by the unique hydride acceptor and donation abilities of the boron Lewis acids used.

2.2.1 Transfer hydrogenation. In 2011, Stephan and coworkers reported the $\mathrm{B}\left(\mathrm{C}_{6} \mathrm{~F}_{5}\right)_{3}$-catalysed transfer hydrogenation of aldimines and ketimines 91 using diisopropylamine (92) as a $\mathrm{H}_{2}$ surrogate (Scheme 18a). ${ }^{30}$ The catalytic cycle (Scheme 18b) proceeds via $\mathrm{B}\left(\mathrm{C}_{6} \mathrm{~F}_{5}\right)_{3}$-mediated hydride abstraction in diisopropylamine (92) to generate iminium 95. Proton transfer from 95 to the substrate imines $\mathbf{9 1}$ and subsequent hydride transfer from the hydridoborate counterion gave amines 93. In agreement with the work reported by Santini and co-workers, ${ }^{9}$ the zwitterion 97 was identified to exist in equilibrium with the ketimine 94 and $B\left(\mathrm{C}_{6} \mathrm{~F}_{5}\right)_{3}$. In addition to imines 91, other classes of molecules such as enamines, a quinoline ( $c f$. 93c) and an aziridine were hydrogenated (Scheme 18c). Stephan's catalytic transfer hydrogenation was applied to the synthesis of the antidepressant sertraline (93a).

2.2.2 Dehydrogenation. In the same issue, both Grimme and Paradies, ${ }^{31}$ and Kanai $^{32}$ reported the $\mathrm{B}\left(\mathrm{C}_{6} \mathrm{~F}_{5}\right)_{3}$-catalysed

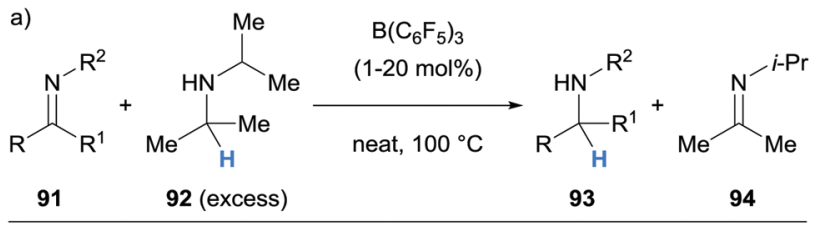

b)
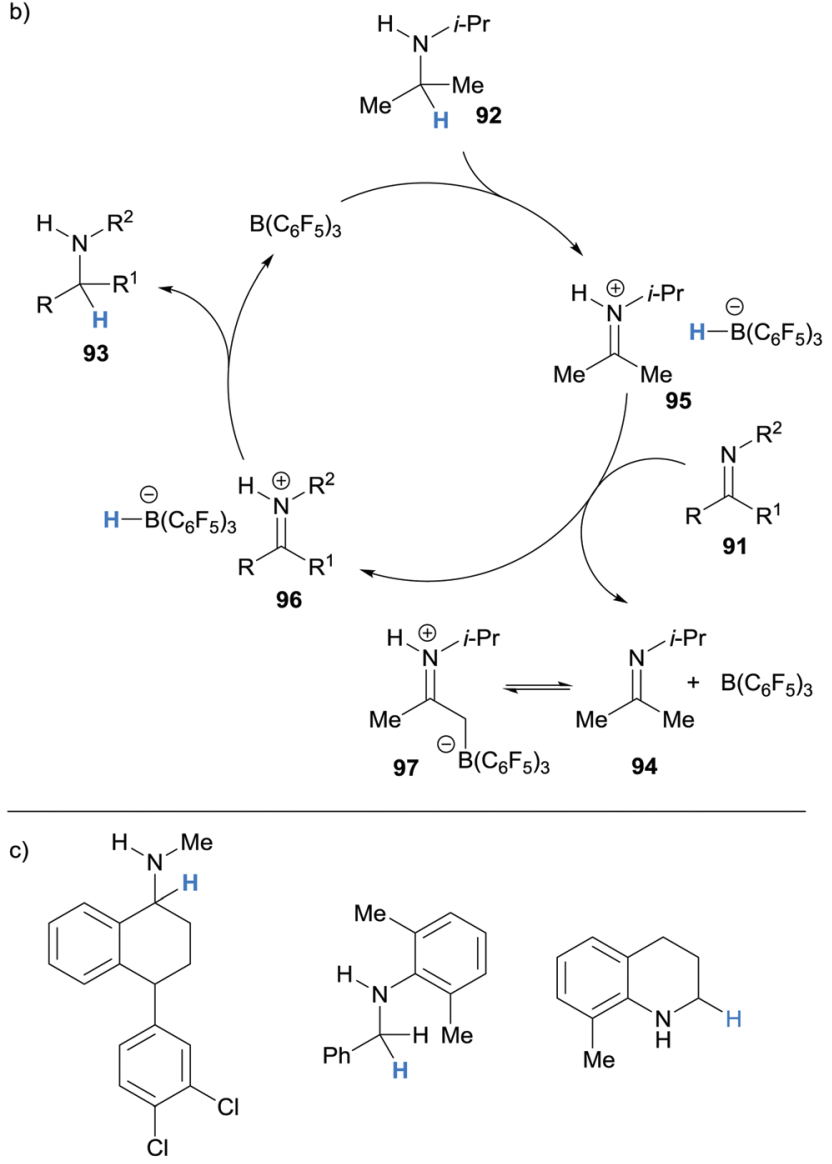

93a, $90 \%$

93b, $98 \%$

$93 c, 56 \%$

Scheme 18 Borane-mediated hydride abstraction utilised in $B\left(C_{6} F_{5}\right)_{3}$ catalysed transfer hydrogenation.

acceptorless dehydrogenation of N-heterocycles (Scheme 19 and 20 , respectively).

Grimme, Paradies and co-workers described the dehydrogenation of a variety of indolines $\mathbf{9 8}$ to the corresponding indoles 99, as well as examples of the dehydrogenation of 1,2-dihydroquinolines ( $c f$. 104), an isoindoline ( $c f$. 105), a benzothiazoline $(c f$. 106) and dihydropyridines $(c f .107)$ in a process mediated by hydride abstraction (Scheme 19a and c). ${ }^{31}$ Using indoles as an example, $\mathrm{B}\left(\mathrm{C}_{6} \mathrm{~F}_{5}\right)_{3}$-mediated hydride abstraction occurred at the $\mathrm{C} 2$ position of indoline $\mathbf{9 8}$ to form iminium 100 (Scheme 19b). The indole product 99 was formed through subsequent deprotonation at the $\mathrm{C} 3$ position by a second equivalent of $\mathbf{9 8}$. Hydrogen gas and the $\mathrm{B}\left(\mathrm{C}_{6} \mathrm{~F}_{5}\right)_{3}$ catalyst were then liberated from the ammonium hydridoborate salt 101 in what was calculated to be the rate limiting step. Interestingly, a rate enhancement was observed upon addition of the weaker Lewis acid $\mathrm{B}\left(2,4,6-\mathrm{F}_{3} \mathrm{C}_{6} \mathrm{H}_{2}\right)_{3}$ (102). Whilst 102 did not 
<smiles>[R]c1cc2c(cc1[R])C([R])([2H])C([R])N2[R1]</smiles><smiles>[R]c1cc2c([R])c([R7])n([Z17])c2cc1[R]</smiles>

b)

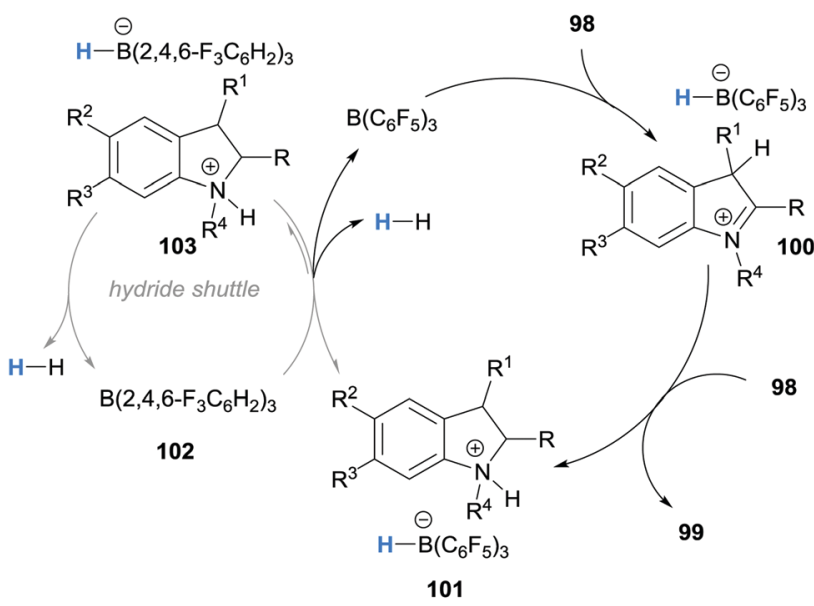

c)<smiles>Cn1c2c(c3ccccc31)CCCC2</smiles><smiles>Cc1cc2cc(Cl)ccc2n1C</smiles><smiles>CCCCc1ccc2cccc([N+](=O)[O-])c2n1</smiles>

99a, $93 \%$

99b, $99 \%$ 104, $93 \%$<smiles>CC(C)(C)n1cc2ccccc2c1</smiles><smiles>c1ccc(-c2nc3ccccc3s2)cc1</smiles>

106, $48 \%$<smiles>CC(=O)c1cc(C(C)=O)c([N+](=O)[O-])nc1C</smiles>

107, $64 \%$

Scheme 19 Borane-mediated hydride abstraction utilised in $B\left(\mathrm{C}_{6} \mathrm{~F}_{5}\right)_{3}$ catalysed acceptorless dehydrogenation.

mediate hydride abstraction, it served as a hydride shuttle whereby the hydridoborate counterion in 103 was more basic than in 101, so that the formation of $\mathrm{H}_{2}$ was more favourable. The hydride shuttle strategy enabled the dehydrogenation of a 1,2-dihydroquinoline ( $c f$. 104), an isoindoline ( $c f$. 105), a benzothiazoline ( $c f$. 106) and dihydropyridines ( $c f .107)$.

Kanai and co-workers reported the $\mathrm{B}\left(\mathrm{C}_{6} \mathrm{~F}_{5}\right)_{3}$-catalysed acceptorless dehydrogenation of $\mathrm{N}$-heterocycles (Scheme 20). ${ }^{32}$ The substrate scope included the dehydrogenation of indolines, tetrahydroquinolines ( $c f$. 109a), tetrahydroquinoxalines ( $c f$. 109c), pyrazolines ( $c f$. 109d) and benzothiazolines ( $c f$. 109e). Notably, coordinating functional groups and atoms, such as thioether and methoxy groups, were tolerated.

Acknowledging the ability of $\mathrm{B}\left(\mathrm{C}_{6} \mathrm{~F}_{5}\right)_{3}$ to catalyse the dehydrogenation of indolines, Zhang and co-workers made use of this in their direct $\mathrm{C} 3 \mathrm{C}-\mathrm{H}$ silylation and borylation approach to

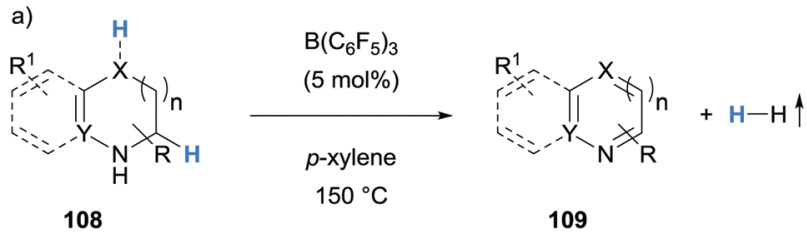

b)<smiles>Cc1ccc2cc(F)ccc2n1</smiles><smiles></smiles><smiles>Cc1nc2ccccc2nc1C</smiles>

109a, $96 \%$

109b, $90 \%$

$109 c, 93 \%$<smiles>c1ccc(-c2cc(-c3ccccc3)n(-c3ccccc3)n2)cc1</smiles><smiles>c1ccc(-c2nc3ccccc3s2)cc1</smiles>

109d, $91 \%$

$109 \mathrm{e}, 91 \%$

Scheme 20 Borane-mediated hydride abstraction utilised in $B\left(C_{6} F_{5}\right)_{3}-$ catalysed acceptorless dehydrogenation.

substituted indoles 112 and 114 (Scheme 21). ${ }^{33,34}$ The initial role of $\mathrm{B}\left(\mathrm{C}_{6} \mathrm{~F}_{5}\right)_{3}$ was to activate the silane or catecholborane to form the weak adduct $\mathbf{1 1 5}$. Adduct 115 then underwent nucleophilic attack by indoles 110, forming the iminium hydridoborate salts 116. Another equivalent of $\mathbf{1 1 0}$ deprotonated 116 to form the desired C3-functionalised product $\mathbf{1 1 2}$ or 114. Hydride transfer within 117 resulted in regeneration of $\mathrm{B}\left(\mathrm{C}_{6} \mathrm{~F}_{5}\right)_{3}$ and formed indolines 113. The disproportionation reaction yields C3-functionalised indole 112 or 114 and indoline 113 at room temperature. In a bid to improve the atom economy, the temperature was increased which promoted the $\mathrm{B}\left(\mathrm{C}_{6} \mathrm{~F}_{5}\right)_{3}$ mediated hydride abstraction and subsequent dehydrogenation of indoline 113 to form indole 110. The dehydrogenation presumably occurred in a related catalytic cycle to that described by Grimme and Paradies ( $c f$. Scheme 19). The catalytic performance of $\mathrm{B}\left(\mathrm{C}_{6} \mathrm{~F}_{5}\right)_{3}$ was investigated by sequentially adding batches of indole and hydrosilane or catecholborane to the same reaction mixture and analysing the yield of desired product each time. The $\mathrm{B}\left(\mathrm{C}_{6} \mathrm{~F}_{5}\right)_{3}$ remained catalytically competent over 10 sequential reactions.

2.2.3 Racemisation and isomerisation. Due to the oftenreversible nature of borane-mediated $\alpha$-amino hydride abstraction, racemisation and isomerisation processes have been found to occur in several cases. In 2011, Repo and co-workers showed that the borane-mediated $\alpha$-hydride abstraction can be used in the racemisation of amines 119 and 120 (Scheme 22). ${ }^{25}$ The racemisation process proceeds via the formation of iminium hydridoborate intermediates after hydride abstraction, followed by a non-face selective hydride transfer to reform the amine. Complete racemisation was observed when enantiomerically enriched amines 119 and 120 were subjected to the $\mathrm{B}\left(\mathrm{C}_{6} \mathrm{~F}_{5}\right)_{3}$ catalyst under an argon atmosphere. Interestingly, in the case of amine 119, racemisation could be fully suppressed when the reaction was performed under $\mathrm{a}_{2}$ atmosphere. 
a)<smiles>CN1[C+]=Cc2cc[R1]cc21</smiles>

$\mathrm{B}\left(\mathrm{C}_{6} \mathrm{~F}_{5}\right)_{3}$

(1-5 mol\%)

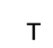

112, $E=\mathrm{SiR}^{1} \mathrm{R}^{2}{ }_{2}$

$114, E=$ Bcat

\begin{tabular}{l|c|cc}
\hline For example: & $\mathrm{T}$ & $112 \mathrm{a}$ & $113 \mathrm{a}$ \\
\cline { 2 - 4 } $\mathrm{R}=5-\mathrm{Ph}, E=\mathrm{SiPh}_{2} \mathrm{Me}$ & $\mathrm{rt}$ & $45 \%$ & $47 \%$ \\
& $120^{\circ} \mathrm{C}$ & $99 \%$ & $0 \%$ \\
\hline
\end{tabular}

b)
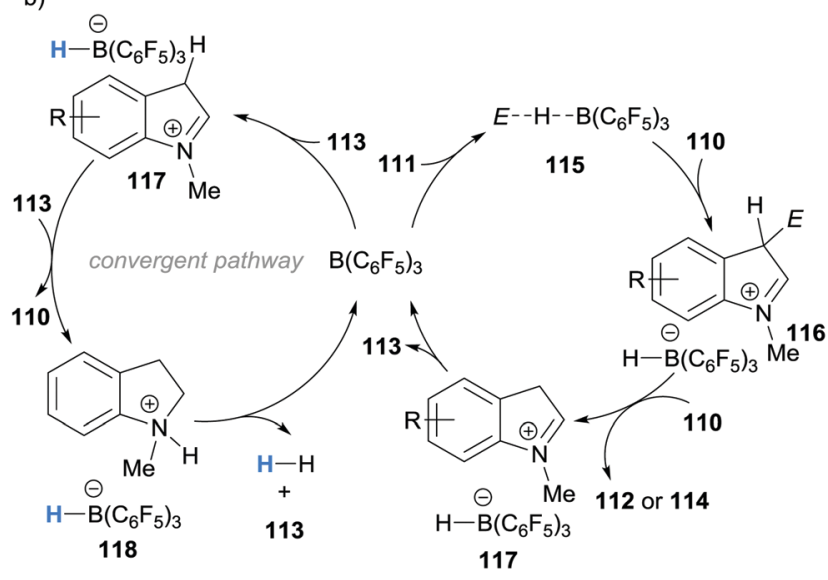

c)<smiles>Cn1cc(F)c2cc(F)ccc21</smiles>

112b, $E=\mathrm{SiPh}_{3}, 92 \%$

114b, $E=$ Bcat, $96 \%$<smiles>O=[W]n1cc(F)c2ccc(Br)cc21</smiles>

112c, $E=\mathrm{SiPh}_{2} \mathrm{Me}, 98 \%$

114c, $E=$ Bcat, $92 \%$

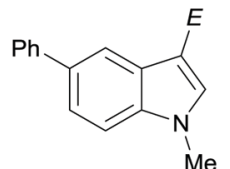

112d, $E=\mathrm{SiPh}_{3}, 99 \%$ 114d, $E=$ Bcat, $95 \%$

Scheme 21 Borane-mediated hydride abstraction utilised in $B\left(C_{6} F_{5}\right)_{3}-$ catalysed convergent C3-silylation and borylation of indoles.<smiles>CC(C)c1cccc2c1N[C@H](c1ccccc1)C2(C)C</smiles>
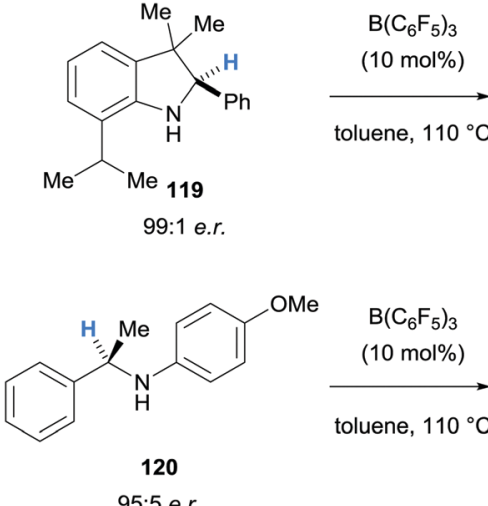

95:5 e.r.

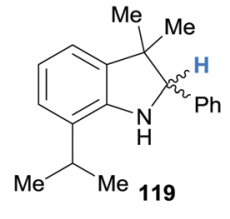

Scheme 22 Borane-mediated hydride abstraction utilised in the racemisation of amines.

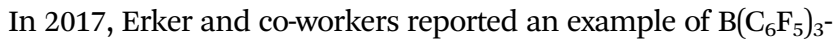
catalysed isomerisation of $\mathrm{N}$-allyltetramethylpiperidine (121) to the a)
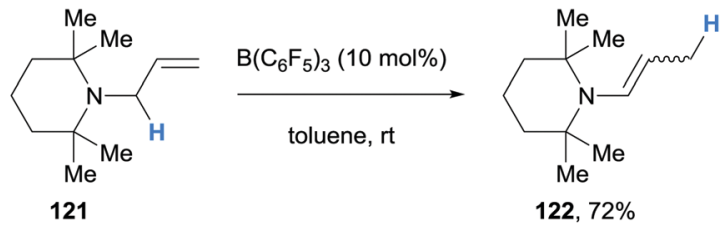

b)

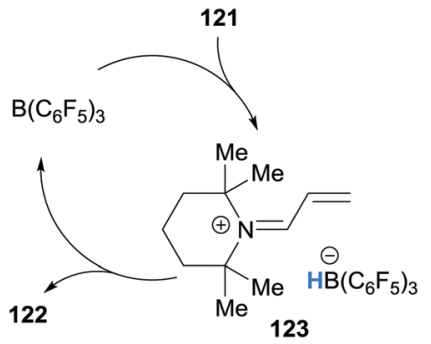

Scheme 23 Borane-mediated hydride abstraction utilised in the isomerisation of an alkene.

corresponding enamine 122 (Scheme 23a). ${ }^{35}$ The authors proposed that isomerisation of $\mathbf{1 2 1}$ occurred via a $\mathrm{B}\left(\mathrm{C}_{6} \mathrm{~F}_{5}\right)_{3}$-mediated hydride abstraction to form $\alpha, \beta$-unsaturated iminium hydridoborate 123 (Scheme 23b). Hydride transfer from the counterion then occurred in a conjugate fashion to form enamine $\mathbf{1 2 2}$ as a mixture of cis-/ trans-isomers.

2.2.4 $\alpha$-Functionalisation of amines. In 2018, Wasa reported the redox neutral, $\mathrm{B}\left(\mathrm{C}_{6} \mathrm{~F}_{5}\right)_{3}$-catalysed $\alpha$-functionalisation of $\mathrm{N}$-alkylamines in a Mannich-type reaction (Schemes 24 and 25). ${ }^{36}$ In this process, amines $\mathbf{1 2 4}$, such as $N$-aryl cyclic amines and tertiary alkyl amines, were coupled to variety of $\alpha, \beta$-unsaturated compounds 125, including $\alpha, \beta$-unsaturated esters, $\alpha, \beta$-unsaturated nitriles, $\alpha, \beta$-unsaturated thioesters, an acetylenedicarboxylate and a maleimide (Schemes 24a and 25a). The mechanism was proposed to proceed via $\mathrm{B}\left(\mathrm{C}_{6} \mathrm{~F}_{5}\right)_{3}$-mediated $\alpha$-amino hydride abstraction in amine 124, forming the iminium hydridoborate 127. The hydride was transferred from the hydridoborate counterion in 127 to the $\alpha, \beta$-unsaturated compound 125, that is itself activated by a Lewis acid catalyst (see below), thus regenerating the $\mathrm{B}\left(\mathrm{C}_{6} \mathrm{~F}_{5}\right)_{3}$ catalyst. Using an $\alpha, \beta$-unsaturated carbonyl as an example, the resultant enolate 129 (or related stabilised carbanions) attacked the iminium 130, affording Mannich product 126. In this strategy, $\mathrm{B}\left(\mathrm{C}_{6} \mathrm{~F}_{5}\right)_{3}$ had a dual role involving hydride abstraction as well as activating the $\alpha, \beta$-unsaturated substrate (Scheme $24 \mathrm{~b}, \mathrm{LA}=$ $\left.\mathrm{B}\left(\mathrm{C}_{6} \mathrm{~F}_{5}\right)_{3}\right)$.

Impressively, Wasa also reported an enantioselective version of the reaction, where a variety of $N$-aryl pyrrolidines 124 and acryloyloxazolidinones $\mathbf{1 3 1}$ were coupled to form Mannich type products 132 with good diastereoselectivity and excellent enantioselectivity (Scheme 25). In this case, the Lewis acid co-catalyst (LA) was derived from $\mathrm{Mg}(\mathrm{OTf})_{2}$ and chiral ligand 133. The selective activation of the acryloyloxazolidinone Michael acceptors $\mathbf{1 3 1}$ by the chiral co-catalyst was crucial to enantioselectivity, and it was suggested that the high steric hindrance of $\mathrm{B}\left(\mathrm{C}_{6} \mathrm{~F}_{5}\right)_{3}$ limited its ability to coordinate to $\mathbf{1 3 1}$.

Wasa and co-workers have also reported Mannich-type reactions involving silyl enol ethers $\mathbf{1 3 4}$ and iminum ions generated via borane-mediated hydride abstraction from $N$-alkylamines 124 
a)<smiles></smiles>

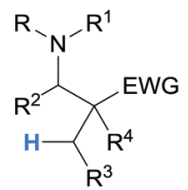

126

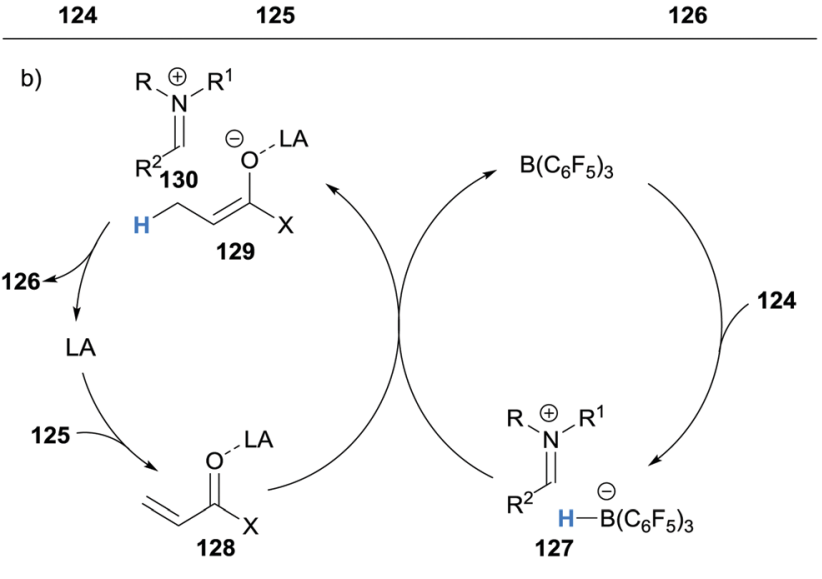

c)

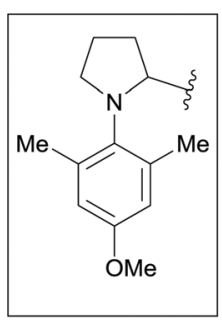<smiles>CC1C=CC(=O)C1C(=O)Nc1ccccc1</smiles><smiles>CC(C#N)C(C)C#N</smiles>

$126 a, 99 \%$ anti:syn $4.5: 1$

126b, $99 \%$

anti:syn 1.2:1<smiles>CC(C)[N+](=O)[O-]</smiles><smiles>C=CC(CN1C(C)(C)CCCC1(C)C)C(=O)[O-]</smiles>

$126 c, 84 \%$

anti:syn 1.2:1

Scheme 24 Borane-mediated $\alpha$-amino hydride abstraction utilised in a redox neutral, $\mathrm{B}\left(\mathrm{C}_{6} \mathrm{~F}_{5}\right)_{3}$-catalysed $\alpha$-functionalisation of $N$-alkylamines. $\mathrm{LA}=$ Lewis acid.

(Scheme 26a). ${ }^{37}$ After generation of the iminium hydridoborates 136, nucleophilic silyl enol ethers 134 react to form a new $\mathrm{C}-\mathrm{C}$ bond and form salt 137. The hydridoborate counterion in $\mathbf{1 3 7}$ was proposed to react with the silyl moiety, thus releasing the $\beta$-amino carbonyl product $\mathbf{1 3 5}$, trimethylsilane and the $\mathrm{B}\left(\mathrm{C}_{6} \mathrm{~F}_{5}\right)_{3}$ catalyst (Scheme 26b). Various amines 124, such as pyrrolidines, $N, N$-dialkylanilines and trialkylamines, were amenable to the process (Scheme 26c). The researchers applied this method to the synthesis of biologically important molecules such as the fluoxetine derivative 135c, a known antidepressant.

Borane-mediated hydride abstraction has also been used in the synthesis of tetrahydroquinolines by the research groups of Grimme and Paradies, ${ }^{38}$ and Wang ${ }^{39}$ (Schemes 27 and 28, respectively). In both cases, $\mathrm{B}\left(\mathrm{C}_{6} \mathrm{~F}_{5}\right)_{3}$-catalysed the efficient conversion of 2-amino styrenes 138 and 145 into tetrahydroquinolines
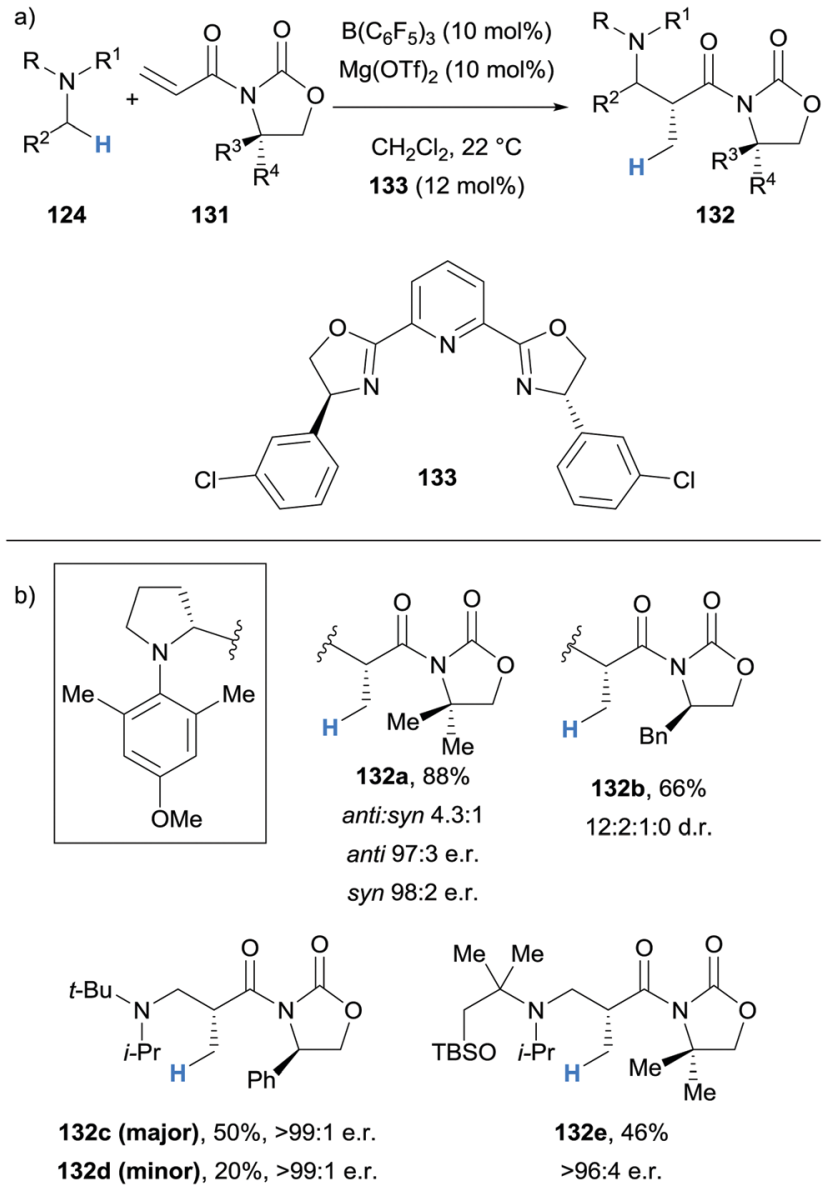

Scheme 25 Borane-mediated hydride abstraction utilised in a redox neutral, $\mathrm{B}\left(\mathrm{C}_{6} \mathrm{~F}_{5}\right)_{3}$-catalysed asymmetric $\alpha$-functionalisation of $N$-alkylamines.

139 and 146. In the Grimme and Paradies study, the mechanism was investigated computationally, and it was proposed that after borane-mediated hydride abstraction to form iminium hydridoborates 140 , a disrotatory $6 \pi$-electrocyclisation occurred to form cationic intermediates 141. Hydride transfer from the hydridoborate anions of $\mathbf{1 4 1}$ formed the desired heterocyclic products 139 and regenerated the $B\left(C_{6} F_{5}\right)_{3}$ catalyst (Scheme 27b). Products that bear $\beta$-amino $\mathrm{C}-\mathrm{H}$ bonds, such as in 139a and 139b, were involved in an off-cycle equilibrium where further $B\left(\mathrm{C}_{6} \mathrm{~F}_{5}\right)_{3}$ mediated hydride abstraction formed enamines 143 and zwitterions 144 in a related process, as observed in other cases ( $c f$. Scheme 6 above). However, $\mathrm{NEt}_{3}$ was used in the work up which converted zwitterion 144 to product 139. It was also shown that stabilisation of the benzylic carbocation in $\mathbf{1 4 1}$ was essential, as only substrates that formed tertiary carbocations were successful in the formation of tetrahydroquinolines 139. Some substrates were prone to autoxidation during the workup ( $c f . \mathbf{1 3 9 b})$.

In the Wang and co-workers $\mathrm{B}\left(\mathrm{C}_{6} \mathrm{~F}_{5}\right)_{3}$-catalysed synthesis of tetrahydroquinolines, $\mathrm{Me}_{3} \operatorname{SiOTf}(20 \mathrm{~mol} \%$ ) was used as an additive, and its role was to accept the hydride from the hydridoborate counterion (Scheme 28). The weaker Lewis acidity of $\mathrm{Me}_{3} \mathrm{SiOTf}$ facilitated subsequent donation of the hydride to the benzylic cation, which was determined to be the ratelimiting step. 


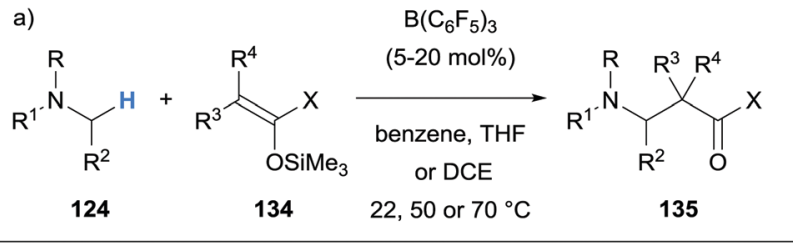

b)

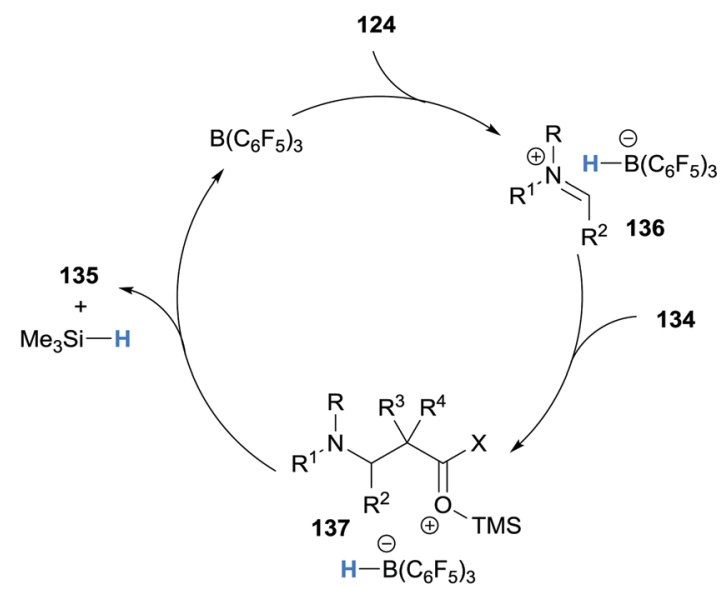

c)<smiles>CCCCCCCCCCC(C)(C)C(=O)OCC</smiles><smiles>COC(=O)C(C)CN1C(C)(C)CCCC1(C)C</smiles>

$135 b, 95 \%$<smiles>COC(=O)C(C)(C)CN(C)CCC(Oc1ccccc1)c1ccccc1</smiles>

$135 \mathrm{c}, 27 \%$<smiles>COC(=O)C(C)CN(C(C)C)C(C)(C)C</smiles>

135d, $93 \%$

Scheme 26 Borane-mediated hydride abstraction utilised in an $\alpha$-functionalisation of $\mathrm{N}$-alkylamines using silyl enol ethers.

2.2.5 $\beta$-Functionalisation of amines. As described above, the resulting iminium hydridoborate salts generated after borane-mediated $\alpha$-amino hydride abstraction often undergo deprotonation to form enamines (see above). The process is often reversible and does not interfere with the desired downstream reactivity. However, several reports have shown that the enamine can be utilised in borane-catalysed $\beta$-functionalisation of amines.

Chang and Park have described the $\mathrm{B}\left(\mathrm{C}_{6} \mathrm{~F}_{5}\right)_{3}$-catalysed formation of polycyclic bridged sila- $N$-heterocycles 149 from $N$-aryl piperidines 147 and methyl phenyl silane (148) (Scheme 29). ${ }^{40}$ Experimental $^{40}$ and theoretical ${ }^{41}$ studies have revealed a triple role for the $\mathrm{B}\left(\mathrm{C}_{6} \mathrm{~F}_{5}\right)_{3}$ catalyst. Firstly, $\mathrm{B}\left(\mathrm{C}_{6} \mathrm{~F}_{5}\right)_{3}$ mediates the hydride abstraction step that enables the formation of iminium hydridoborate $\mathbf{1 5 0}$ and subsequent formation of enamine $\mathbf{1 5 1}$

a)

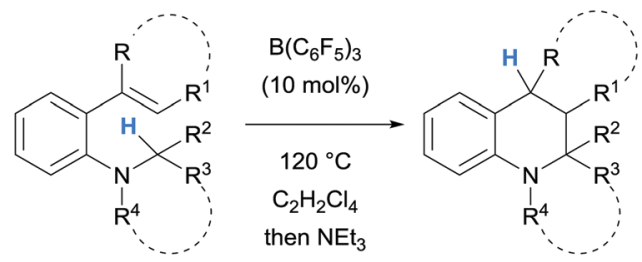

138

139

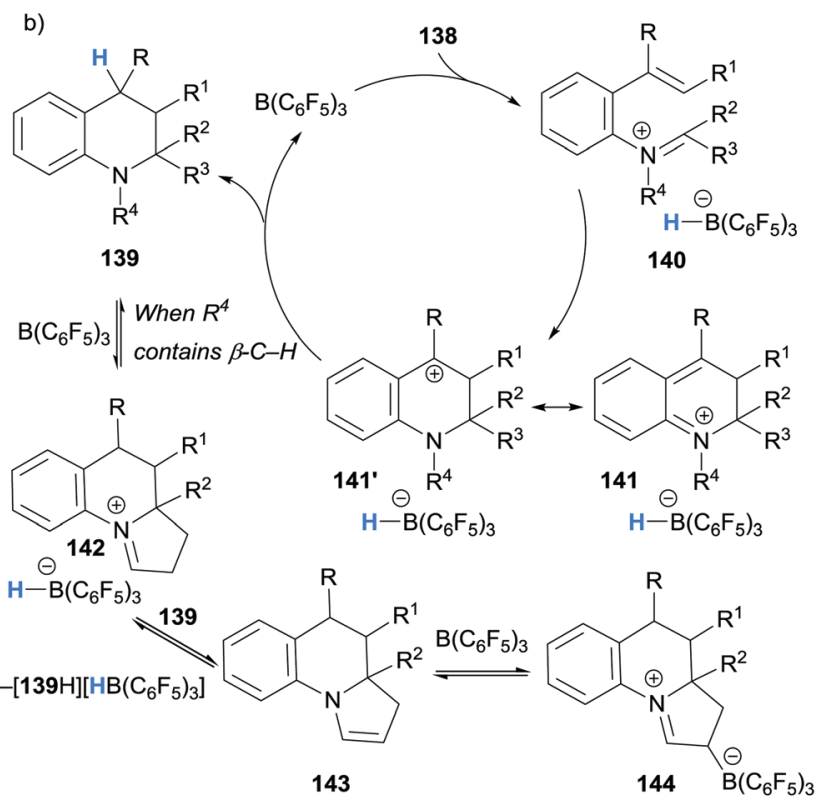

c) 139a, $98 \%$

d.r. 1.1:1

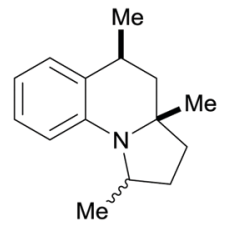

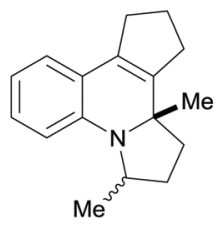

139b, $78 \%$

d.r. 2.4:1

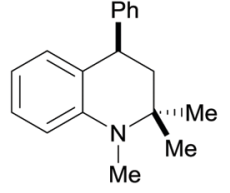

139c, $93 \%$
Scheme 27 Borane-mediated hydride abstraction utilised in the $B\left(\mathrm{C}_{6} \mathrm{~F}_{5}\right)_{3}$ catalysed synthesis of tetrahydroquinolines.

in a related process to that previously described ( $c f$. Scheme 6). Piperidinium borohydride $\mathbf{1 5 2}$ then releases hydrogen to regenerate $\mathrm{B}\left(\mathrm{C}_{6} \mathrm{~F}_{5}\right)_{3}$. The second role of $\mathrm{B}\left(\mathrm{C}_{6} \mathrm{~F}_{5}\right)_{3}$ is to activate methyl phenyl silane (148) for nucleophilic addition by enamine 151. Hydride transfer from the hydridoborate counterion to the iminium moiety in 153 provides amine 154. Finally, $B\left(C_{6} F_{5}\right)_{3}$ activates the $\mathrm{Si}-\mathrm{H}$ bond for electrophilic silylation of the aromatic ring in 154, which subsequently releases hydrogen to form polycyclic bridged sila-N-heterocycles 149 . The additive $\mathrm{CaO}$ was used and proposed to assist with the proton transfer steps of the ionic cascade mechanism.

$\mathrm{Ma}$ and co-workers reported the $\beta$-alkylation of acyclic tertiary amines 156 with para-quinone methides 157 (Scheme 30). ${ }^{42}$ The $\mathrm{B}\left(\mathrm{C}_{6} \mathrm{~F}_{5}\right)_{3}$-mediated hydride abstraction of amines 156 allowed for the formation of ammonium hydridoborate 160 and enamine 161. Conjugate addition between the nucleophilic enamine 161 
a)<smiles>[R]C(=C)c1ccc2ccccc2c1N([R])C([R])C</smiles>

$\mathrm{B}\left(\mathrm{C}_{6} \mathrm{~F}_{5}\right)_{3}(10 \mathrm{~mol} \%)$ $\mathrm{Me}_{3} \mathrm{SiOTf}(20 \mathrm{~mol} \%)$

toluene, $25-140{ }^{\circ} \mathrm{C}$

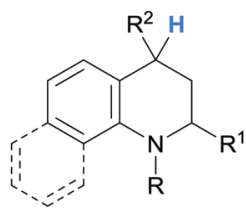

145

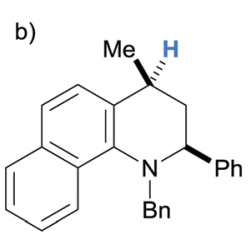

146a, 97\% cis:trans $14: 1$

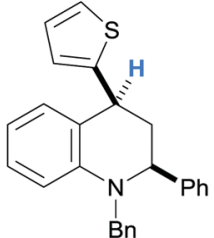

146b, $88 \%$

cis:trans 10:1
146

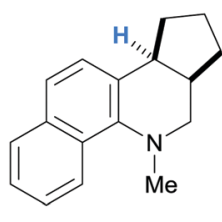

146c, $86 \%$
Scheme 28 Borane-mediated hydride abstraction utilised in the $\mathrm{B}\left(\mathrm{C}_{6} \mathrm{~F}_{5}\right)_{3}$ catalysed synthesis of tetrahydroquinolines.
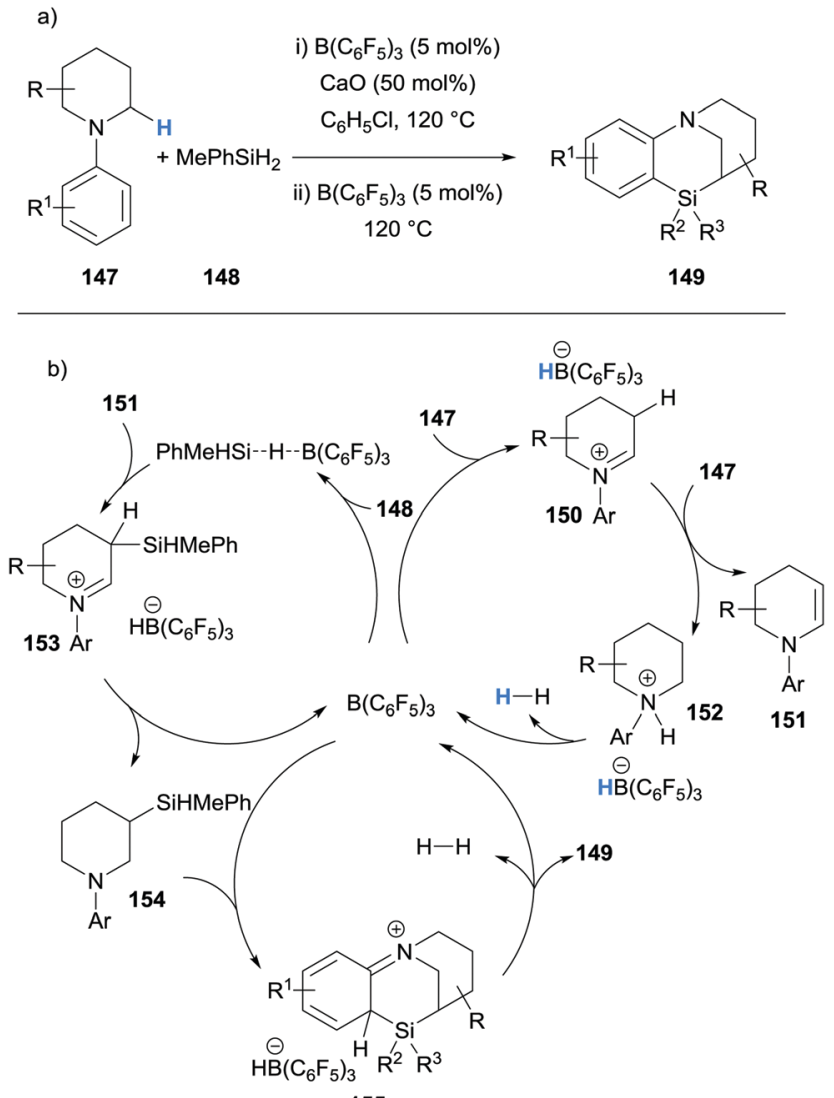

155

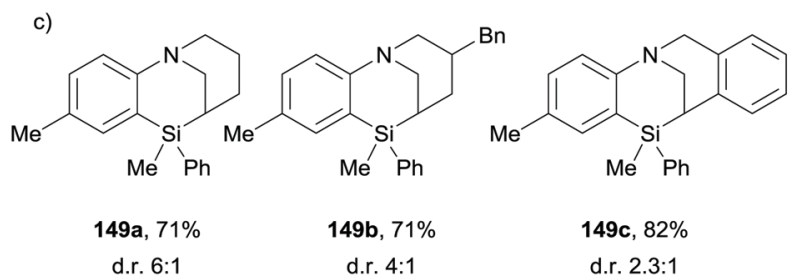

Scheme 29 Borane-mediated hydride abstraction utilised in a $B\left(C_{6} F_{5}\right)_{3}$ catalysed silylative cascade.
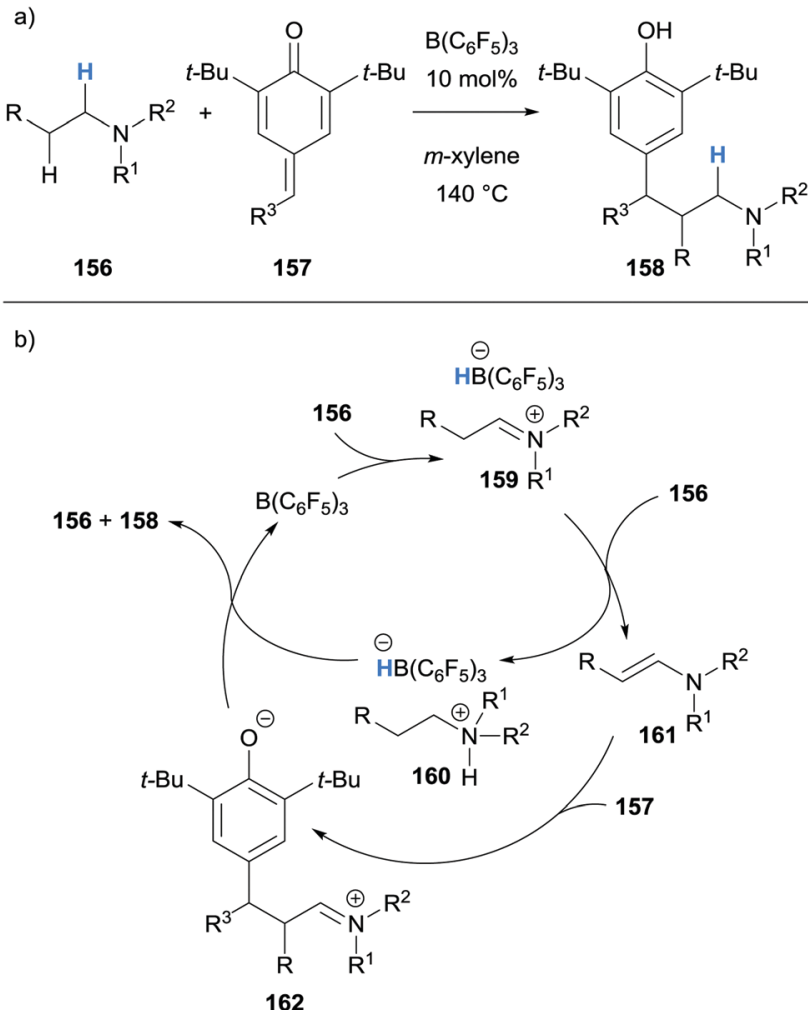

c)<smiles>CCCCCCC(CC(C)c1cccs1)N(CC)CC</smiles><smiles>CCN(CC)CCC(C)c1ccc2ccccc2c1</smiles>

Scheme 30 Borane-mediated hydride abstraction utilised in a $B\left(C_{6} F_{5}\right)_{3}$ catalysed $\beta$-amino alkylation.

and para-quinone methide 157 occurred to produce iminium 162. Protonation of 162 and hydride transfer from the ammonium hydridoborate 160 yielded $\beta$-functionalised product 158. An unsymmetrical tertiary amine was reacted where $\beta$-functionalisation occurred preferentially on ethyl instead of the $n$-butyl chain.

In 2019, Wasa showed that borane-mediated $\alpha$-amino hydride abstraction could be used to efficiently deuterate $\beta$-amino $\mathrm{C}-\mathrm{H}$ bonds of $N$-alkyamines 163, including pharmaceutical compounds (Scheme 31). ${ }^{43}$ As seen before, $\mathrm{B}\left(\mathrm{C}_{6} \mathrm{~F}_{5}\right)_{3}$ mediated the formation of ammonium hydridoborate 166 and enamine 167. It was proposed that $\mathrm{B}\left(\mathrm{C}_{6} \mathrm{~F}_{5}\right)_{3}$ also has the role of mediating FLP-like deprotonation of deuterated acetone (164) to form ammonium borate 169, which serves as the deuterium source for the deuteration of enamine 167. Impressively, pharmaceutically 
a) 163 164

163-d

b)

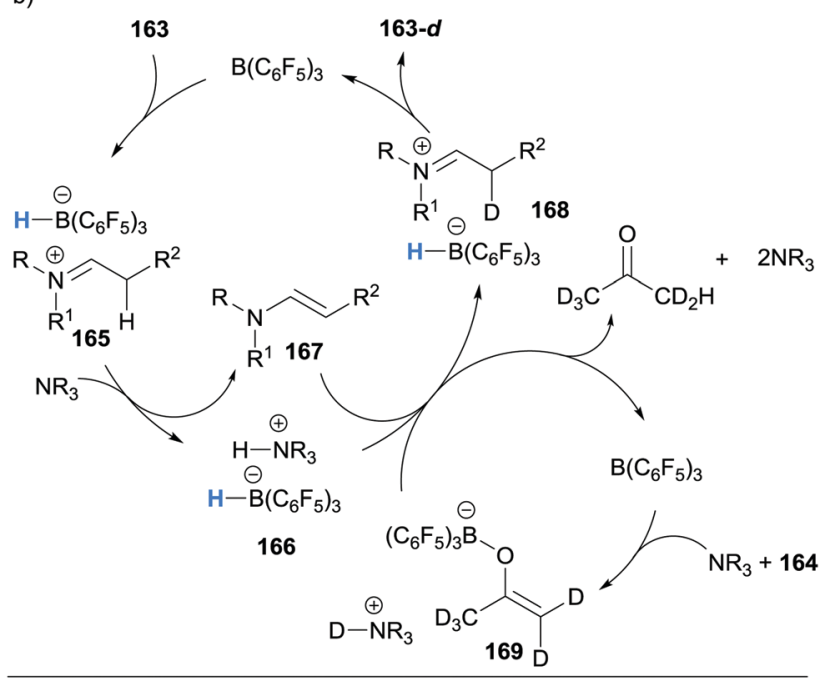

c)

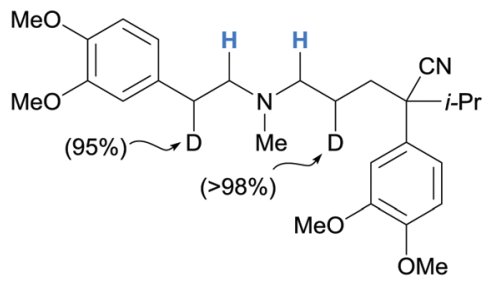<smiles>CC(C)(C)OCCOc1ccc2c(c1)OCO2</smiles>

$163 c-d, 95 \%$

Scheme 31 Borane-mediated hydride abstraction utilised in a $\left.\mathrm{B}_{(6} \mathrm{C}_{6} \mathrm{~F}_{5}\right)_{3}$ catalysed $\beta$-amino deuteration. Parenthesis refer to \%D incorporation.

active compounds, with some containing Lewis acid-sensitive functional groups such as cyano, ester, amide and ketones, were successfully deuterated.

2.2.6 $\mathrm{C}-\mathrm{N}$ bond cleavage. Borane-mediated hydride abstraction has also been used in challenging catalytic $\mathrm{C}-\mathrm{N}$ bond breaking processes, such as in the use of amines as novel alkylating agents, and in the dealkylation of amines (including ring deconstruction).

In 2020, we reported the application of borane-mediated $\alpha$-amino hydride abstraction in a $\mathrm{B}\left(\mathrm{C}_{6} \mathrm{~F}_{5}\right)_{3}$-catalysed $\mathrm{C} 3$ alkylation a)<smiles>[R]c1cc2ccccc2n1[R]</smiles><smiles>[R]N1C(=O)Cc2ccccc21</smiles>

$\mathrm{H}_{2} \mathrm{O} \cdot \mathrm{B}\left(\mathrm{C}_{6} \mathrm{~F}_{5}\right)_{3}(10-20 \mathrm{~mol} \%)$ $\mathrm{Et}_{3} \mathrm{SiH}(20-40 \mathrm{~mol} \%)$

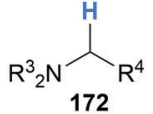<smiles>[R]c1c(C([R])[2H])c2ccccc2n1[R]</smiles>

DCE, toluene or $p$-xylene $25-150^{\circ} \mathrm{C}$<smiles>[Y10]N1C(=O)C(C[2H])c2ccccc21</smiles>

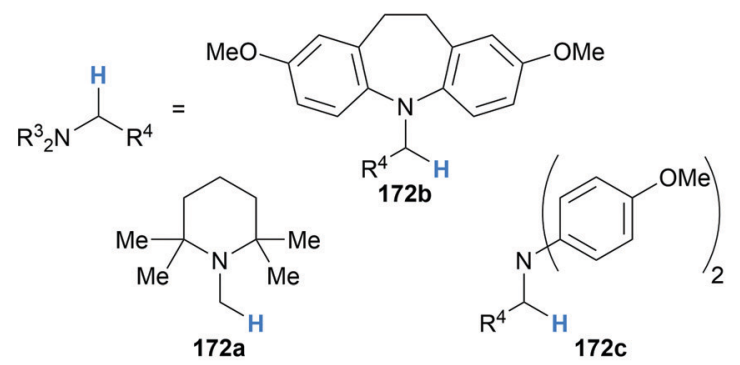

b) $\mathrm{H}_{2} \mathrm{O} \cdot \mathrm{B}\left(\mathrm{C}_{6} \mathrm{~F}_{5}\right)_{3}$

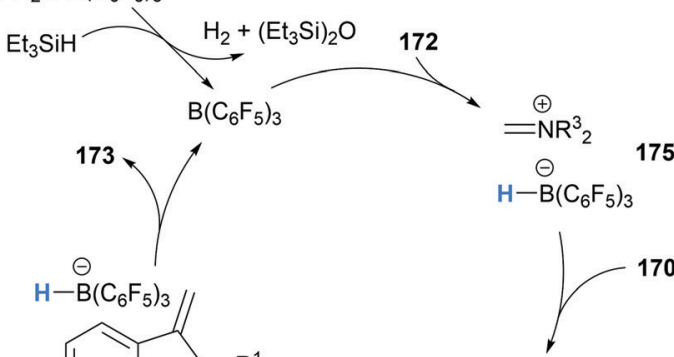<smiles></smiles>

$177 \mathrm{R}$

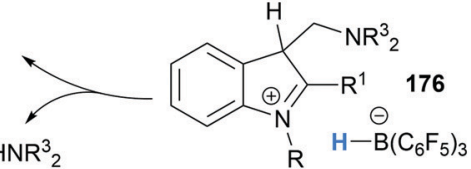<smiles>Cc1[nH]c2ccc(Cl)cc2c1C</smiles>

$173 a, 98 \%$<smiles>C=CC1C(=O)N(c2ccccc2)c2ccc(OC)cc21</smiles>

$174 a, 75 \%$<smiles></smiles>

$173 b, 95 \%$

Scheme 32 Borane-mediated hydride abstraction utilised in a $\mathrm{B}\left(\mathrm{C}_{6} \mathrm{~F}_{5}\right)_{3}$ catalysed alkylation of indoles and oxindoles.

of indoles and oxindoles that utilised amine based alkylating agents (Scheme 32). ${ }^{44}$ The mechanism was proposed to begin with the generation of iminium hydridoborate 175 after $B\left(C_{6} F_{5}\right)_{3}$ mediated hydride abstraction of the alkylating agent 172. The iminium 175 underwent nucleophilic attack by the indole $\mathbf{1 7 0}$ (or oxindole 171) to form a new $\mathrm{C}-\mathrm{C}$ bond. Subsequent proton transfers resulted in the formation of $\alpha, \beta$-unsaturated iminium 177, presumably via an E1cB-like elimination. Hydride transfer from the hydridoborate counterion to $\mathbf{1 7 7}$ allowed the formation of alkylated indoles 173 (and oxindoles 174). 


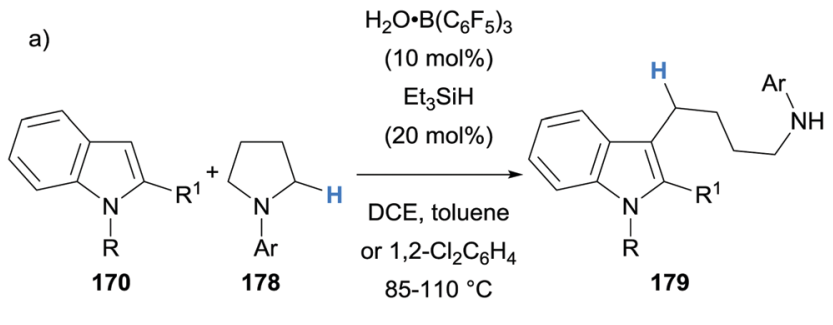

b) $\mathrm{H}_{2} \mathrm{O} \cdot \mathrm{B}\left(\mathrm{C}_{6} \mathrm{~F}_{5}\right)_{3}$
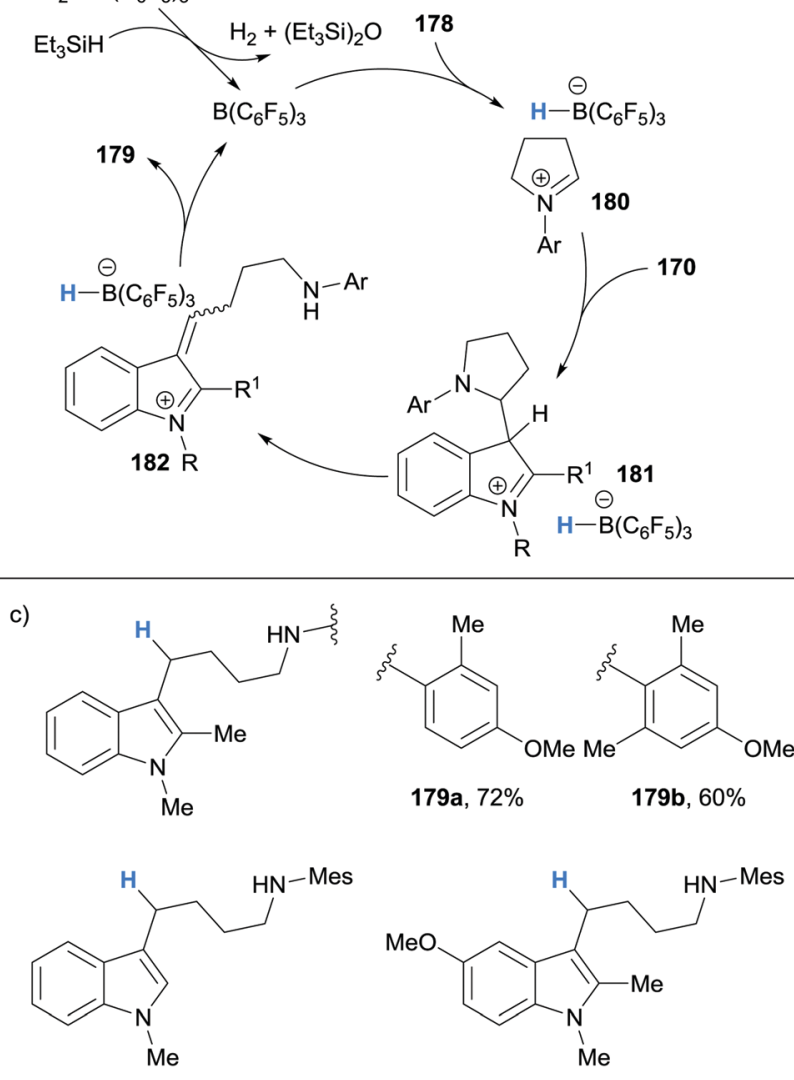

179c, $75 \%$

$179 a, 72 \%$

$179 b, 60 \%$

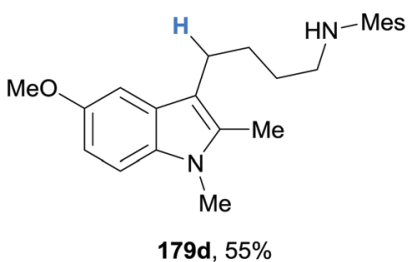

Scheme 33 Borane-mediated hydride abstraction utilised in a $\mathrm{B}\left(\mathrm{C}_{6} \mathrm{~F}_{5}\right)_{3}$ catalysed alkylation-ring opening cascade.

In the same report, we also reported the use of boranemediated hydride abstraction in a ring-opening cascade process between indoles 170 and pyrrolidines 178 to form 4-(3-indolyl)butylamines 179, a privileged motif found in several serotonergic/ dopaminergic drug molecules (Scheme 33). ${ }^{44}$ The mechanism was proposed to proceed in a similar fashion to the previously described alkylation process ( $c f$. Scheme 32 ), except the cyclic nature of amine $\mathbf{1 7 8}$ allowed for the amine portion to be retained in product 179 after elimination (Scheme 33). The use of $\mathrm{Et}_{3} \mathrm{SiH}$ (20 mol\%) serves to free the $\mathrm{B}\left(\mathrm{C}_{6} \mathrm{~F}_{5}\right)_{3}$ catalyst from its water adduct in situ. This modification allowed the authors to directly use $\mathrm{B}\left(\mathrm{C}_{6} \mathrm{~F}_{5}\right)_{3}$ as received from the supplier and weigh it in air on the open bench, thus negating the use of a glove box and additional catalyst purification.

Chang and co-workers described the use of borane-mediated hydride abstraction in a dehydrogenation/ $\beta$-silylation/C-N bond
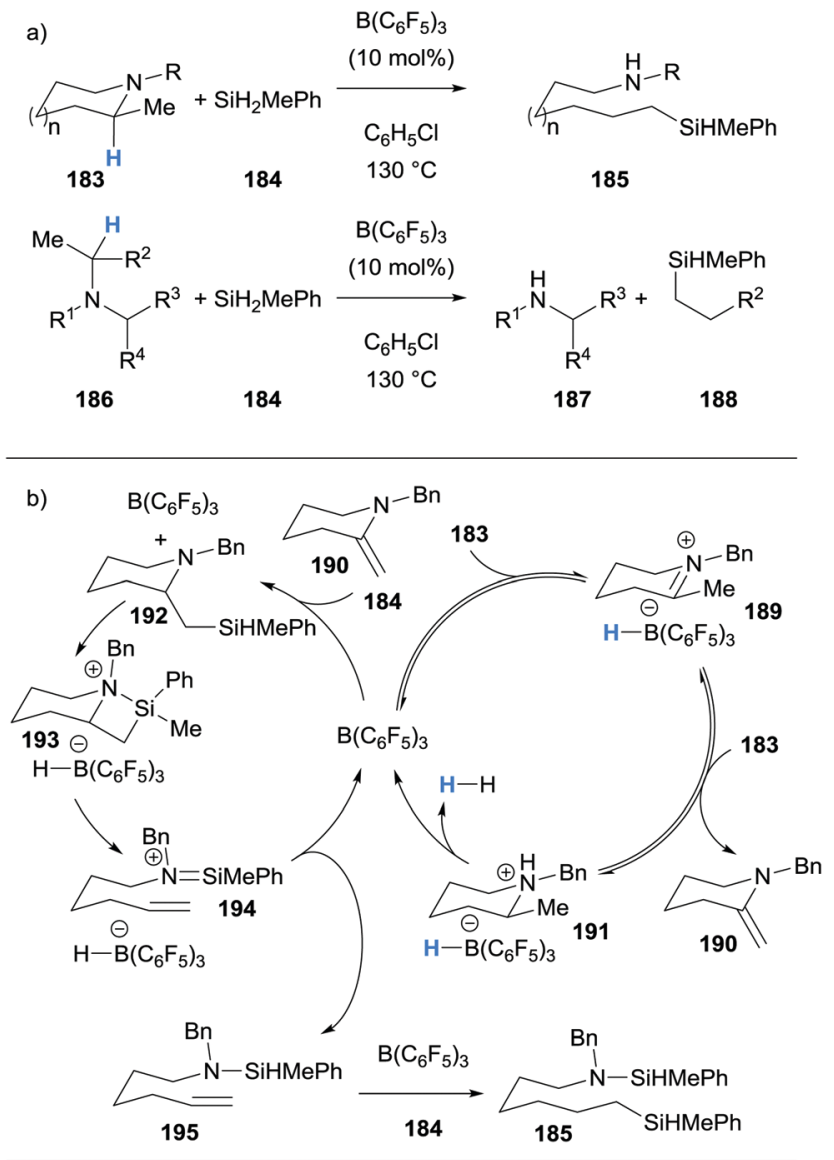

c)

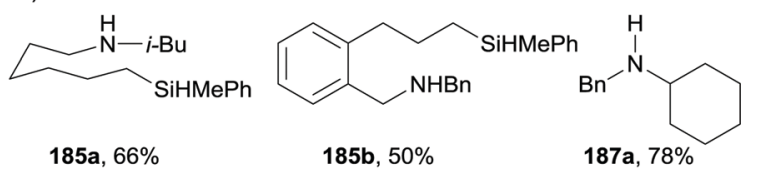

Scheme 34 Borane-mediated hydride abstraction utilised in a $B\left(C_{6} F_{5}\right)_{3}$ catalysed cine-silylative ring opening and tertiary amines deconstruction processes.

cleavage cascade process (Scheme 34). ${ }^{45}$ Cyclic tertiary amines (183) underwent cine-silylative ring opening to form amines $\mathbf{1 8 5}$, and tertiary amines (186) underwent deconstruction to form secondary amines 187 and alkyl silanes 188. Impressively, $\mathrm{B}\left(\mathrm{C}_{6} \mathrm{~F}_{5}\right)_{3}$ has multiple roles in these processes. Using the cinesilylative ring opening to illustrate the mechanism, cyclic amines 183 undergo $\mathrm{B}\left(\mathrm{C}_{6} \mathrm{~F}_{5}\right)_{3}$-catalysed dehydrogenation to form enamines 190 and ammonium hydridoborate 191 in the rate limiting step. $\mathrm{B}\left(\mathrm{C}_{6} \mathrm{~F}_{5}\right)_{3}$-catalysed $\beta$-silylation of enamines 190 with silanes 184 then gave silylated amine 192. Amine 192 is predisposed to form silazetidinium intermediate 193 via $\mathrm{B}\left(\mathrm{C}_{6} \mathrm{~F}_{5}\right)_{3}$-mediated activation of the $\mathrm{Si}-\mathrm{H}$ bond. Cycloreversion cleaved the $\mathrm{C}-\mathrm{N}$ bond in 193 and gave 194, which after hydride transfer from the hydridoborate counterion, gave amino alkene 195. $B\left(\mathrm{C}_{6} \mathrm{~F}_{5}\right)_{3}$-catalysed hydrosilylation of the alkene moiety in $\mathbf{1 9 5}$ allowed the formation of product 185. Interestingly, theoretical and experimental investigations revealed that borane-mediated hydride abstraction preferentially occurred at the more substituted carbon of the 
ring ( $c f$. formation of 189) and that exo-enamine 190 formation was more favoured than the corresponding endo-enamine.

\section{Borane-mediated $\gamma$-amino hydride abstraction}

In contrast to $\alpha$-amino hydride donors, donation from a $\gamma$-amino conjugated $\mathrm{C}-\mathrm{H}$ bond will be more familiar. 1,4-Dihydropyridines are well studied hydride donors in both a biological (e.g. NADH) and chemical (e.g. Hantzsch esters) setting. ${ }^{1}$ However, $\gamma$-hydride abstraction of conjugated amines with boranes has received relatively little attention. In this section, stoichiometric investigations of hydride abstraction from 1,4-dihydropyridines and 2-alkylideneimidazolines will be discussed. An application of this reactivity in transfer hydrogenation will also be included.

\subsection{Stoichiometric studies}

3.1.1 1,4-Dihydropyridines. In 2010, Crudden, Stephan and co-workers studied the $\mathrm{B}\left(\mathrm{C}_{6} \mathrm{~F}_{5}\right)_{3}$-mediated hydride abstraction in a series of Hantzsch ester analogues 196a-196e (Scheme 35). ${ }^{46}$ Hantzsch esters 196a-196d underwent $\gamma$-amino hydride abstraction to form pyridinium hydridoborates 197a-197d in good yields at low temperatures. The $\mathrm{B}\left(\mathrm{C}_{6} \mathrm{~F}_{5}\right)_{3}$ adduct $198 \mathrm{c}$ of the Hantzsch ester 196c was also observed. In the case of the keto derivative 196e, only the $\mathrm{B}\left(\mathrm{C}_{6} \mathrm{~F}_{5}\right)_{3}$ adduct 198e was observed. Upon warming the pyridinium hydridoborates 197a-197d, the $\mathrm{B}\left(\mathrm{C}_{6} \mathrm{~F}_{5}\right)_{3}$ adduct of 1,2-dihydropyridines 199 were formed, presumably via hydride transfer from the hydridoborate counterion to the pyridinium cation via 1,2-addition.

Inspired by the naturally occurring organic hydride donor $\mathrm{NAD}(\mathrm{P}) \mathrm{H}$, Melen and co-workers studied the $\mathrm{B}\left(\mathrm{C}_{6} \mathrm{~F}_{5}\right)_{3}$-mediated hydride abstraction of $N$-benzyl-1,4-dihydropyridine derivatives (200a-200c). ${ }^{47}$ The reaction between $N$-benzyl-1,4-dihydropyridine 200a and $\mathrm{B}\left(\mathrm{C}_{6} \mathrm{~F}_{5}\right)_{3}$ afforded pyridinium borohydride 201a in excellent yield via $\gamma$-amino hydride abstraction (Scheme 36a). A similar outcome was observed when carboxylic acid substituted 1,4dihydropyridine 200b was treated with $\mathrm{B}\left(\mathrm{C}_{6} \mathrm{~F}_{5}\right)_{3}$ (Scheme 36b).

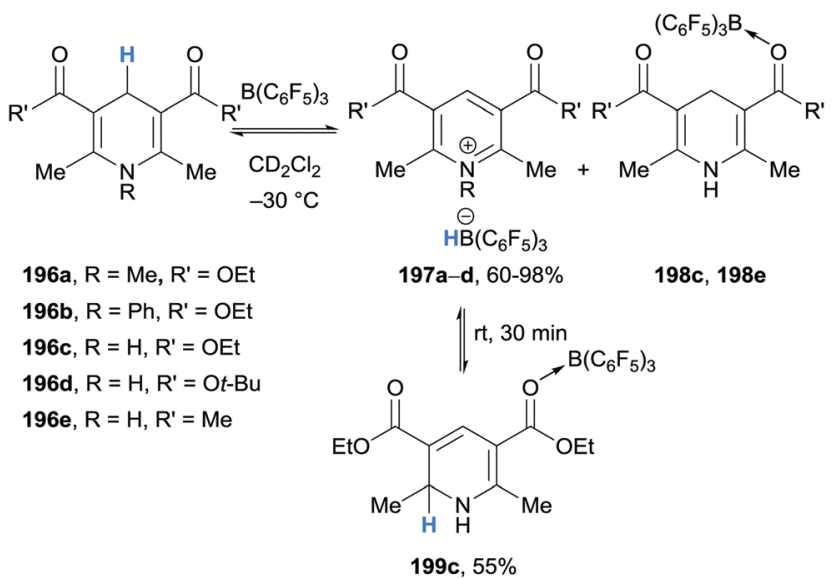

Scheme 35 Borane-mediated $\gamma$-amino hydride abstraction from Hantzsch ester derivatives. a)
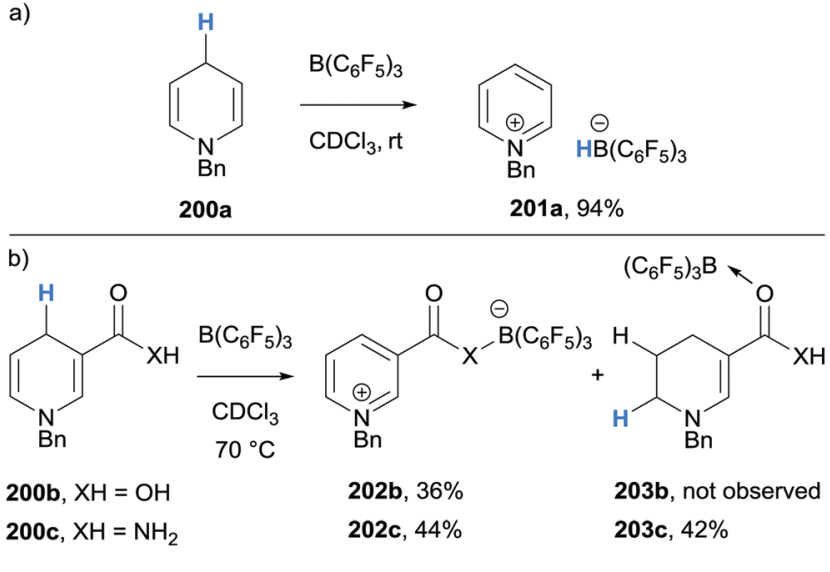

c) Oxidation:

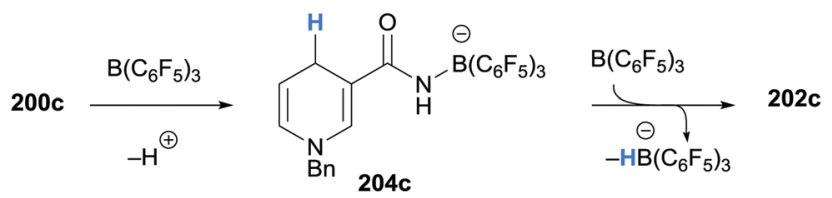

Reduction:

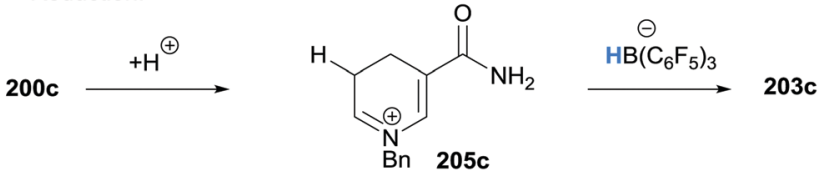

Scheme 36 Borane-mediated $\gamma$-amino hydride abstraction from 1,4dihydropyridine derivatives.

Interestingly, when nicotinamide derivative 200c was reacted with $\mathrm{B}\left(\mathrm{C}_{6} \mathrm{~F}_{5}\right)_{3}$, a disproportionation was observed and pyridinium borate zwitterion 202c and $\mathrm{B}\left(\mathrm{C}_{6} \mathrm{~F}_{5}\right)_{3}$ coordinated 1,2-dihydropyridine 203c were formed. The mechanism, supported by deuterium labelling experiments, was proposed to involve initial coordination of $\mathrm{B}\left(\mathrm{C}_{6} \mathrm{~F}_{5}\right)_{3}$ to nicotinamide derivative 200c to acidify the $\mathrm{N}-\mathrm{H}$ bond and allow protonation of another molecule of 200c (Scheme 36c). Borane-mediated hydride abstraction then formed a hydridoborate counterion that transfers a hydride to the iminium moiety in 205c.

3.1.2 2-Alkylideneimidazoline. In 2013, Tamm and co-workers widened the scope of borane-mediated $\gamma$-amino hydride abstraction to include acyclic enamines. When 2-alkylideneimidazoline derivatives 206a-206b that possess $\gamma$-amino $\mathrm{C}\left(\mathrm{sp}^{3}\right)-\mathrm{H}$ bonds were reacted with $\mathrm{B}\left(\mathrm{C}_{6} \mathrm{~F}_{5}\right)_{3}$, 2-vinylimidazolium hydridoborates 207a-207b were formed (Scheme 37). ${ }^{48}$

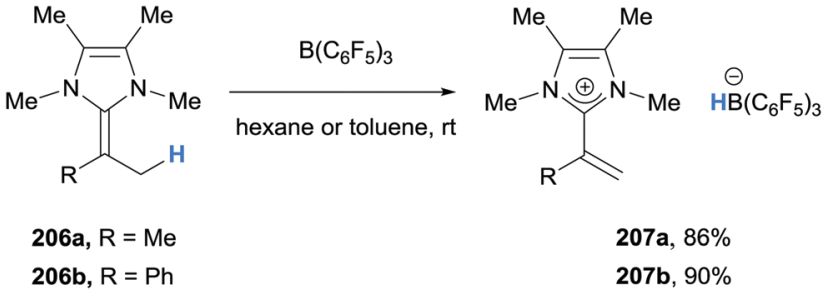

Scheme 37 Borane-mediated $\gamma$-amino hydride abstraction from 2-alkylideneimidazolines. 

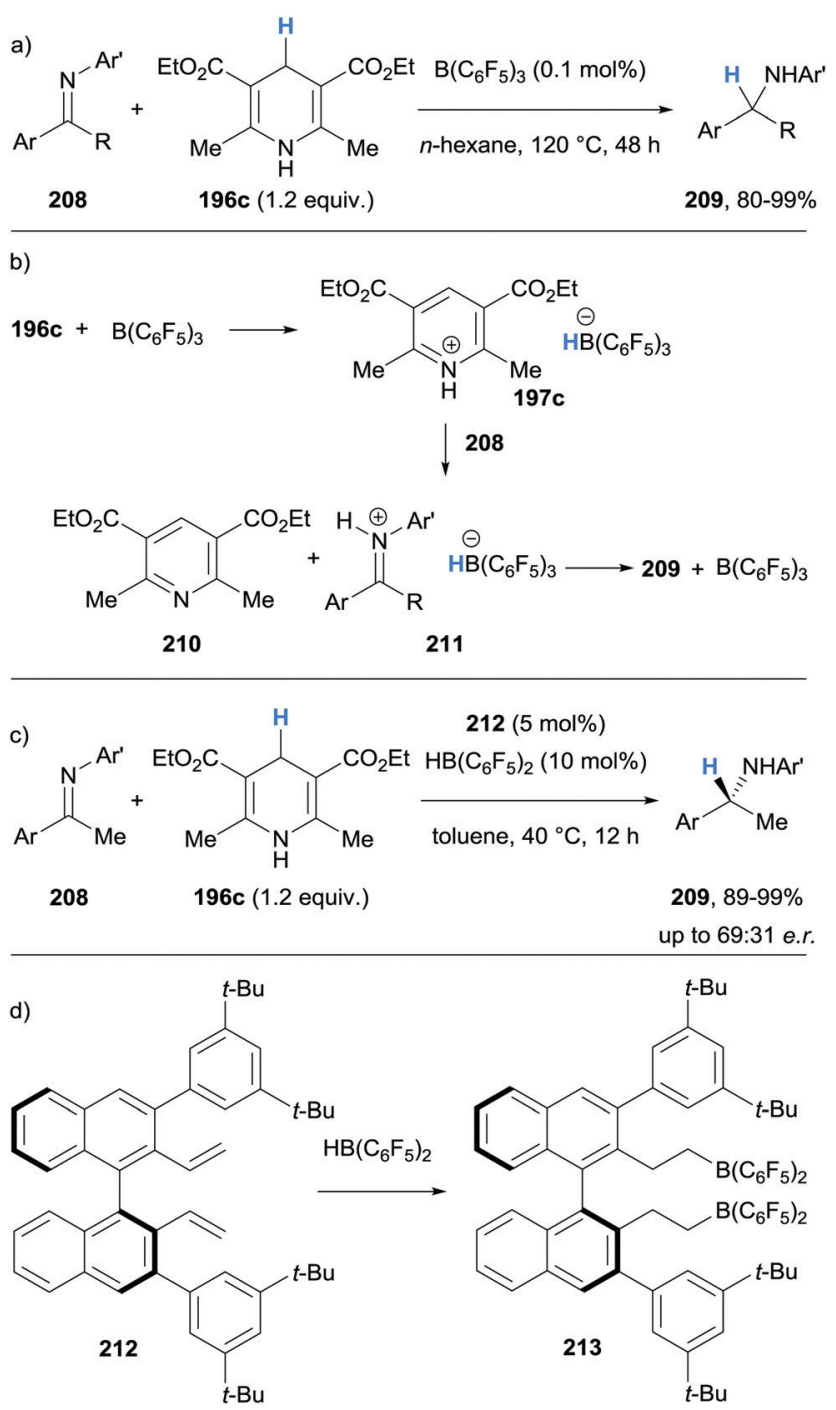

Scheme 38 Borane-mediated $\gamma$-amino hydride abstraction from Hantzsch esters utilised in the $\mathrm{B}\left(\mathrm{C}_{6} \mathrm{~F}_{5}\right)_{3}$-catalysed transfer hydrogenation of imines.

\subsection{Catalytic applications}

3.2.1 Transfer hydrogenation. Related to Crudden, Stephan and co-workers' study of borane-mediated $\gamma$-amino hydride abstraction involving Hantzsch esters, Du and co-workers reported the $\mathrm{B}\left(\mathrm{C}_{6} \mathrm{~F}_{5}\right)_{3}$-catalysed transfer hydrogenation of imines (Scheme 38). ${ }^{49}$ Remarkably, as little as 0.1 mol\% loading of $\mathrm{B}\left(\mathrm{C}_{6} \mathrm{~F}_{5}\right)_{3}$ was effective. The key iminium hydridoborate salt 211, formed after borane-mediated hydride abstraction and proton transfer, was proposed to be the key intermediate where hydride transfer occurs from the hydridoborate counterion to the electrophilic iminium. ${ }^{50}$ Furthermore, work towards an enantioselective transfer hydrogenation of imines 208 was also reported, whereby an enantiomerically enriched borane 213 was used as a catalyst. Borane 213 was formed via an in situ hydroboration of divinyl BINAP derivative 212 with $\mathrm{HB}\left(\mathrm{C}_{6} \mathrm{~F}_{5}\right)_{2}$.

\section{Summary and outlook}

Borane-mediated hydride abstraction has been observed in a variety of amino substrates. The most common substrate class reported are amines that bear $\alpha$-amino $\mathrm{C}-\mathrm{H}$ bonds where, in stoichiometric studies, iminium hydridoborates have been observed. There are a variety of chemical reactions that the iminium hydridoborate generated can undergo, which include proton transfers to form enamines, nucleophilic addition to the electrophilic iminium, and further hydride transfers.

Due to the array of reactions that both the iminium and hydridoborate ions can undergo, borane-mediated hydride abstraction has been employed as a key event in many powerful borane-catalysed processes. These include novel strategies for reagent activation, such as the use of amines as $\mathrm{H}_{2}$ surrogates in transfer hydrogenation, and as alkylating agents. In addition, new methods for the manipulation of amines, including dehydrogenation, racemisation, isomerisation, $\alpha$ - and $\beta$-functionalisation, and $\mathrm{C}-\mathrm{N}$ bond cleavage have all been reported. The application of these methods in synthesis has demonstrated the high functional group tolerance possible in processes involving borane-mediated hydride abstraction. Borane-mediated hydride abstraction involving $\gamma$-amino conjugated $\mathrm{C}-\mathrm{H}$ bonds has also been reported.

Borane-mediated hydride abstraction is a relatively young field and there is no doubt that advances will continue to be made. By far the most commonly used borane has been $\mathrm{B}\left(\mathrm{C}_{6} \mathrm{~F}_{5}\right)_{3}$, likely because it is commercially available, robust and well-established use in the borane catalysis arena. However, we expect that optimisation of the borane structure will be a fruitful endeavour with respect to tuning regio- and chemo-selectivity. In addition, asymmetric processes are poorly represented with respect to borane-mediated hydride abstraction and we anticipate growth in this area. Furthermore, expansion of the amine scope with respect to other classes of conjugated amines may lead to valuable methods involving remote functionalisation. Given the great interest, especially from the pharmaceutical industry, ${ }^{6,7}$ in efficient synthetic methods that manipulate $\mathrm{C}-\mathrm{H}$ bonds of amines, borane-mediated hydride abstraction will continue to be exploited in novel processes.

\section{Conflicts of interest}

There are no conflicts to declare.

\section{Acknowledgements}

L. W. and A. P. P. thank the School of Chemistry, University of Leicester, for their generous support and the Royal Society for a Research Grant (No. RGS $\backslash$ R1 $\backslash 191082)$. S. B., B. A. K., R. L. M., and L. C. M. gratefully acknowledge the School of Chemistry, Cardiff University for generous support, the Leverhulme Trust for a Research Project Grant (No. RPG-2015-361), and the Schlumberger Foundation for a Faculty for the Future Fellowship (B. A. K.). R. L. M. would like to acknowledge the EPSRC for a research fellowship (No. EP/R026912/1). 


\section{Notes and references}

1 E. S. Wiedner, M. B. Chambers, C. L. Pitman, R. M. Bullock, A. J. M. Miller and A. M. Appel, Chem. Rev., 2016, 116, 8655-8692, and references therein.

2 S. Ilic, A. Alherz, C. B. Musgrave and K. D. Glusac, Chem. Soc. Rev., 2018, 47, 2809-2836, and references therein.

3 J. C. L. Walker and M. Oestreich, Synlett, 2019, 2216-2232.

4 S. Keess and M. Oestreich, Chem. Sci., 2017, 8, 4688-4695.

5 M. Oestreich, Angew. Chem., Int. Ed., 2016, 55, 494-499.

6 J. F. Allochio Filho, B. C. Lemos, A. S. de Souza, S. Pinheiro and S. J. Greco, Tetrahedron, 2017, 73, 6977-7004.

7 D. C. Blakemore, L. Castro, I. Churcher, D. C. Rees, A. W. Thomas, D. M. Wilson and A. Wood, Nat. Chem., 2018, 10, 383-394.

8 B. Temme and G. Erker, J. Organomet. Chem., 1995, 488, 177-182.

9 N. Millot, C. C. Santini, B. Fenet and J. M. Basset, Eur. J. Inorg. Chem., 2002, 3328-3335.

10 L. E. Garner, H. Zhu, M. L. Hlavinka, J. R. Hagadorn and E. Y.-X. Chen, J. Am. Chem. Soc., 2006, 128, 14822-14823.

11 T. Voss, T. Mahdi, E. Otten, R. Fröhlich, G. Kehr, D. W. Stephan and G. Erker, Organometallics, 2012, 31, 2367-2378.

12 A. D. Saverio, F. Focante, I. Camurati, L. Resconi, T. Beringhelli, G. D'Alfonso, D. Donghi, D. Maggioni, P. Mercandelli and A. Sironi, Inorg. Chem., 2005, 44, 5030-5041.

13 V. Sumerin, F. Schulz, M. Nieger, M. Leskelä, T. Repo and B. Rieger, Angew. Chem., Int. Ed., 2008, 47, 6001-6003.

14 C. Jiang, O. Blacque, T. Fox and H. Berke, Organometallics, 2011, 30, 2117-2124.

15 F. Focante, P. Mercandelli, A. Sironi and L. Resconi, Coord. Chem. Rev., 2006, 250, 170-188.

16 F. Focante, PhD thesis, University of Bologna, 2005.

17 F. Focante, I. Camurati, D. Nanni, R. Leardini and L. Resconi, Organometallics, 2004, 23, 5135-5141.

18 P. Liptau, M. Neumann, G. Erker, G. Kehr, R. Fröhlich and S. Grimme, Organometallics, 2004, 23, 21-25.

19 L. Tebben, M. Neumann, G. Kehr, R. Fröhlich, G. Erker, S. Losi and P. Zanello, Dalton Trans., 2006, 1715-1720.

20 J.-B. Sortais, T. Voss, G. Kehr, R. Fröhlich and G. Erker, Chem. Commun., 2009, 7417-7418.

21 K. Unverhau, G. Lübbe, B. Wibbeling, R. Fröhlich, G. Kehr and G. Erker, Organometallics, 2010, 29, 5320-5329.

22 A. D. Saverio, F. Focante, I. Camurati, L. Resconi, T. Beringhelli, G. D’Alfonso, D. Donghi, D. Maggioni, P. Mercandelli and A. Sironi, Inorg. Chem., 2005, 44, 5030-5041.

23 J. Chen and E. X.-Y. Chen, Molecules, 2015, 20, 9575-9590.

24 G.-Q. Chen, G. Kehr, C. G. Daniliuc, M. Bursch, S. Grimme and G. Erker, Chem. - Eur. J., 2017, 23, 4723-4729.

25 V. Sumerin, K. Chernichenko, M. Nieger, M. Leskelä, B. Rieger and T. Repo, Adv. Synth. Catal., 2011, 353, 2093-2110.

26 S. Schwendemann, R. Fröhlich, G. Kehr and G. Erker, Chem. Sci., 2011, 2, 1842-1849.

27 D. Winkelhaus, B. Neumann, H.-G. Stammler, R. J. F. Berger, Y. V. Vishnevskiy and N. W. Mitzel, Chem. - Eur. J., 2012, 18, 9312-9320.
28 L. A. Körte, S. Blomeyer, S. Heidemeyer, J. H. Nissen, A. Mix, B. Neumann, H.-G. Stammler and N. W. Mitzel, Dalton Trans., 2016, 45, 17319-17328.

29 T. Wang, L. Liu, S. Grimme, C. G. Daniliuc, G. Kehr and G. Erker, Chem. - Asian J., 2016, 11, 1394-1399.

30 J. M. Farrell, Z. M. Heiden and D. W. Stephan, Organometallics, 2011, 30, 4497-4500.

31 A. F. G. Maier, S. Tussing, T. Schneider, U. Flörke, Z.-W. Qu, S. Grimme and J. Paradies, Angew. Chem., Int. Ed., 2016, 55, 12219-12223.

32 M. Kojima, M. Kanai and J. Paradies, Angew. Chem., Int. Ed., 2016, 55, 12224-12227.

33 Y. Han, S. Zhang, J. He and Y. Zhang, J. Am. Chem. Soc., 2017, 139, 7399-7407.

34 S. Zhang, Y. Han, J. He and Y. Zhang, J. Org. Chem., 2018, 83, 1377-1386.

35 T. Wang, L. Wang, C. G. Daniliuc, K. Samigullin, M. Wagner, G. Kehr and G. Erker, Chem. Sci., 2017, 8, 2457-2463.

36 M. Shang, J. Z. Chan, M. Cao, Y. Chang, Q. Wang, B. Cook, S. Torker and M. Wasa,J. Am. Chem. Soc., 2018, 140, 10593-10601.

37 J. Z. Chan, Y. Chang and M. Wasa, Org. Lett., 2019, 21, 984-988.

38 A. F. G. Maier, S. Tussing, H. Zhu, G. Wicker, P. Tzvetkova, U. Flörke, C. G. Daniliuc, S. Grimme and J. Paradies, Chem. Eur. J., 2018, 24, 16287-16291.

39 J.-J. Tian, N.-N. Zeng, N. Lie, X.-S. Tu and X.-C. Wang, ACS Catal., 2019, 9, 295-300.

40 J. Zhang, S. Park and S. Chang, J. Am. Chem. Soc., 2018, 140, 13209-13213.

41 M. Zhou, S. Park and L. Dang, Org. Chem. Front., 2020, 7, 944-952.

42 R. Li, Y. Chen, K. Jiang, F. Wang, C. Lu, J. Nie, Z. Chen, G. Yang, Y.-C. Chen, Y. Zhao and C. Ma, Chem. Commun., 2019, 55, 1217-1220.

43 Y. Chang, A. Yesilcimen, M. Chao, Y. Zhang, B. Zhang, J. Z. Chan and M. Wasa, J. Am. Chem. Soc., 2019, 141, 14570-14575.

44 S. Basak, A. Alvarez-Montoya, L. Winfrey, R. L. Melen, L. C. Morrill and A. P. Pulis, ACS Catal., 2020, 10, 4835-4840.

45 J. Zhang and S. Chang, J. Am. Chem. Soc., 2020, 142, 12585-12590.

46 J. D. Webb, V. S. Laberge, S. J. Geier, D. W. Stephan and C. M. Crudden, Chem. - Eur. J., 2010, 16, 4895-4902.

47 L. C. Wilkins, N. Santi, L. Y. P. Luk and R. L. Melen, Philos. Trans. R. Soc., A, 2017, 375, 20170009.

48 S. Kronig, P. G. Jones and M. Tamm, Eur. J. Inorg. Chem., 2013, 2301-2314.

49 Q. Wang, J. Chen, X. Feng and H. Du, Org. Biomol. Chem., 2018, 16, 1448-1451.

50 Alternative mechanisms for the $\mathrm{B}\left(\mathrm{C}_{6} \mathrm{~F}_{5}\right)_{3}$-catalysed transfer hydrogenation of aldehydes, $p$-quinone methides and fuchsones using Hantzsch ester as the hydrogen source have been proposed to occur via $\mathrm{B}\left(\mathrm{C}_{6} \mathrm{~F}_{5}\right)_{3}$ activation of the reduction substrate prior to hydride transfer directly from the Hantzsch ester. See: A. Hamasaka, H. Tsuji, M. Ehara and Y. Uozumi, RSC Adv., 2019, 9, 10201-10210. 